Universidad de Lima

Escuela de Posgrado

Maestría en Tributación y Política Fiscal

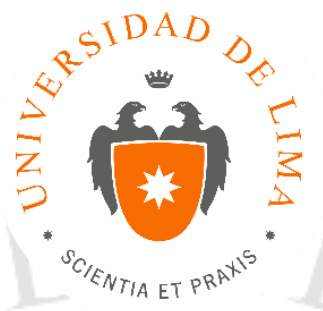

\title{
LOS CONTRATOS DE CASH POOLING: APLICACIÓN Y TRATAMIENTO TRIBUTARIO, VINCULADO A LA REGLA SUBCAPITALIZACIÓN
}

Trabajo de investigación para optar el Grado Académico de Maestro en

Tributación y Política Fiscal

Crosbyl Leo Quispe Borda

Código 20132486

\author{
Asesores \\ Carla Mares Ruiz \\ Ramón Bueno Tizón Vivar
}

Lima - Perú

Julio de 2017 


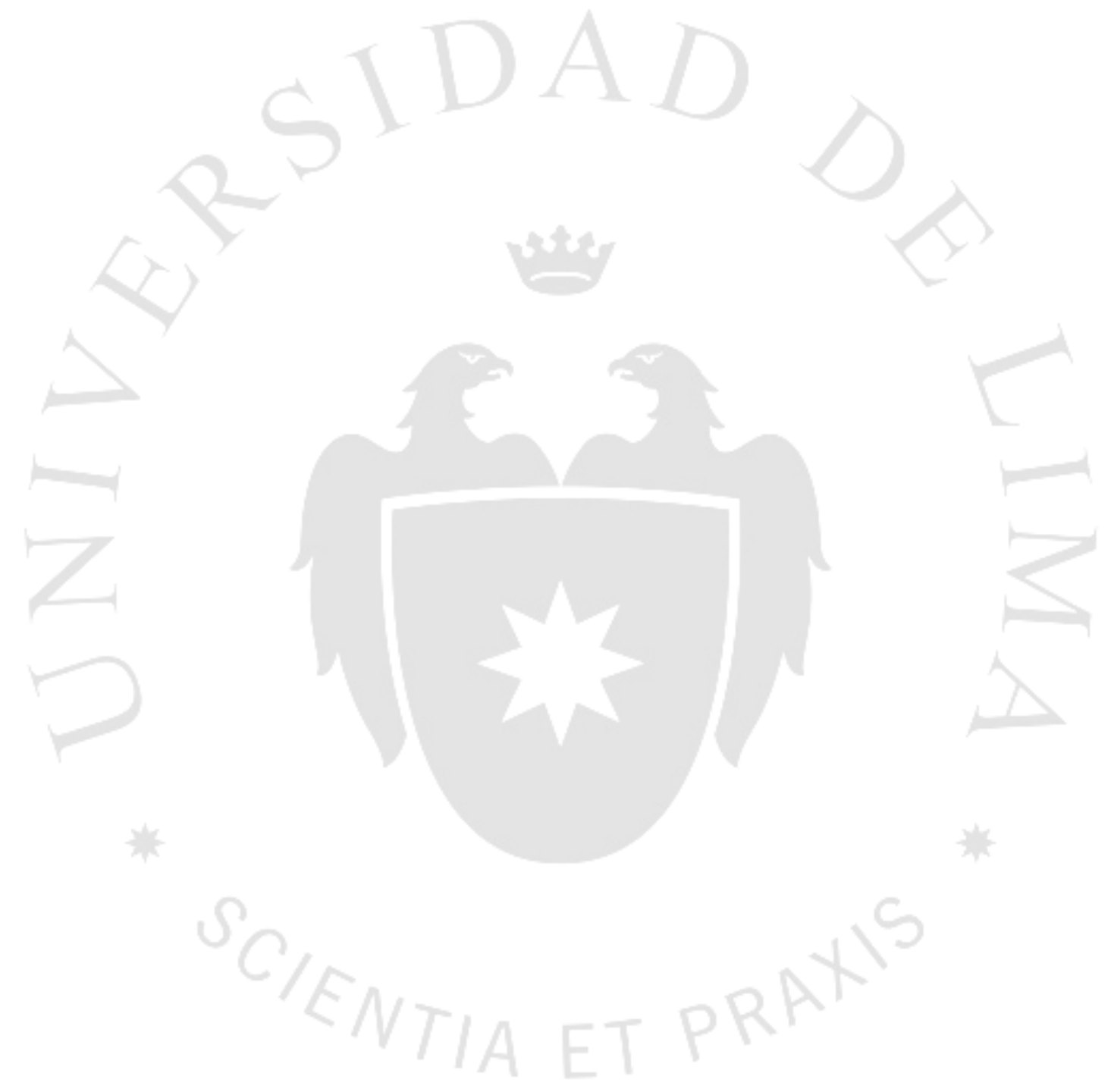




\section{LOS CONTRATOS DE CASH POOLING:}

APLICACIÓN Y TRATAMIENTO

\section{TRIBUTARIO, VINCULADO A LA REGLA SUBCAPITALIZACIÓN}




\section{TABLA DE CONTENIDO}

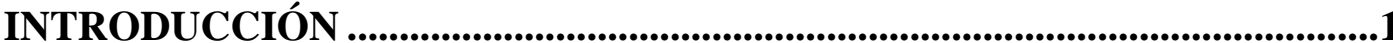

\section{CAPÍTULO I: ACERCAMIENTO A LOS CONTRATOS DE CASH POOLING}

3

1.1 Conceptualización de los contratos de cash pooling .............................3

1.2 Ventajas, objetivos, y desventajas del contrato de cash pooling ............4

1.2.1 Ahorro en costes financieros y ventajas económicas: ........................5

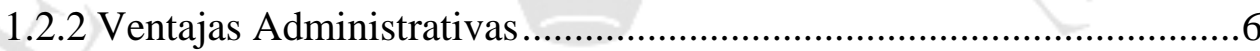

1.2.3 Desventajas de la implementación ..................................................6

1.3 Tipos de Contratos de Cash Pooling ...............................................

1.3.1 Cash Pooling de Balance Cero (ZBA): ............................................

1.3.2 Cash Pooling Nocional o Virtual: ...............................................8

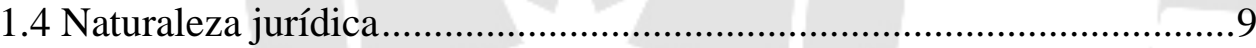

1.4.1 De acuerdo a la legislación y doctrina comparada. ..........................10

1.4.2 El símil en la legislación y doctrina local.........................................11

CAPÍTULO II: LA REGLA DE SUBCAPITALIZACIÓN, Y SU INCLUSIÓN EN LA LEY DEL IMPUESTO A LA RENTA Y LA LEGISLACIÓN COMPARADA 12

2.1 Definición y naturaleza de la regla de subcapitalización ........................12

2.1.1 Perspectiva societaria y financiera ...............................................12

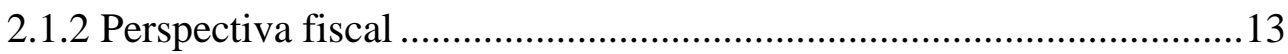

2.1.3 Métodos para evitar el fenómeno de la subcapitalización ....................14

2.1.4 Características de la regla de subcapitalización ................................15

2.2 Inclusión en la Ley el IR ..............................................................18

2.3 Características de la Regla de Subcapitalización en la LIR ...................19 
2.3.1 Adopción del método objetivo 19

2.3.2 Financiamiento con partes vinculadas ......................................20

2.3.3 Endeudamiento directo e indirecto ...........................................20

2.4 Tratamiento en la legislación comparada........................................22

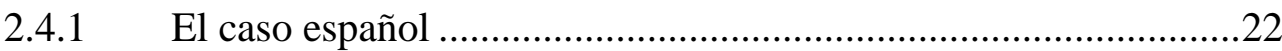

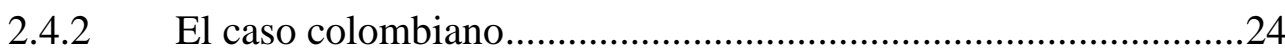

\section{CAPÍTULO III: INTERPRETACIÓN DE LAS NOMAS TRIBUTARIAS EN EL} PERÚ

3.1.1 Normas del Código Tributario.....................................................27

3.2 Técnicas o métodos de interpretación del derecho ................................28

3.2.1 Técnicas o métodos de interpretación del derecho en general .............28

3.2.2 Principios de interpretación de la ley tributaria ..................................31

3.2.3 Métodos de interpretación genéricos en el derecho tributario...............36

3.3 Interpretación del artículo 37.a) de la Ley del IR .................................41

3.3.1 Interpretación literal de la regla de subcapitalización .........................41

3.3.2 Interpretación teleológica y sistemática de la regla de subcapitalización 43

\section{CAPÍTULO IV: APLICACIÓN DE LA REGLA DE SUBCAPITALIZACIÓN, EN EL MARCO DE LOS CONTRATOS DE CASH POOLING ..........................47}

4.1 Los objetivos de los contratos de cash pooling, y su repercusión fiscal 47

4.2 La naturaleza de la regla de subcapitalización, y su inclusión en la Ley del IR 48

4.3 Utilización del método teleológico y sistemático, en la interpretación de la regla de subcapitalización .50

4.4 Sobre la aplicabilidad de la regla de subcapitalización en los contratos de cash pooling .52 


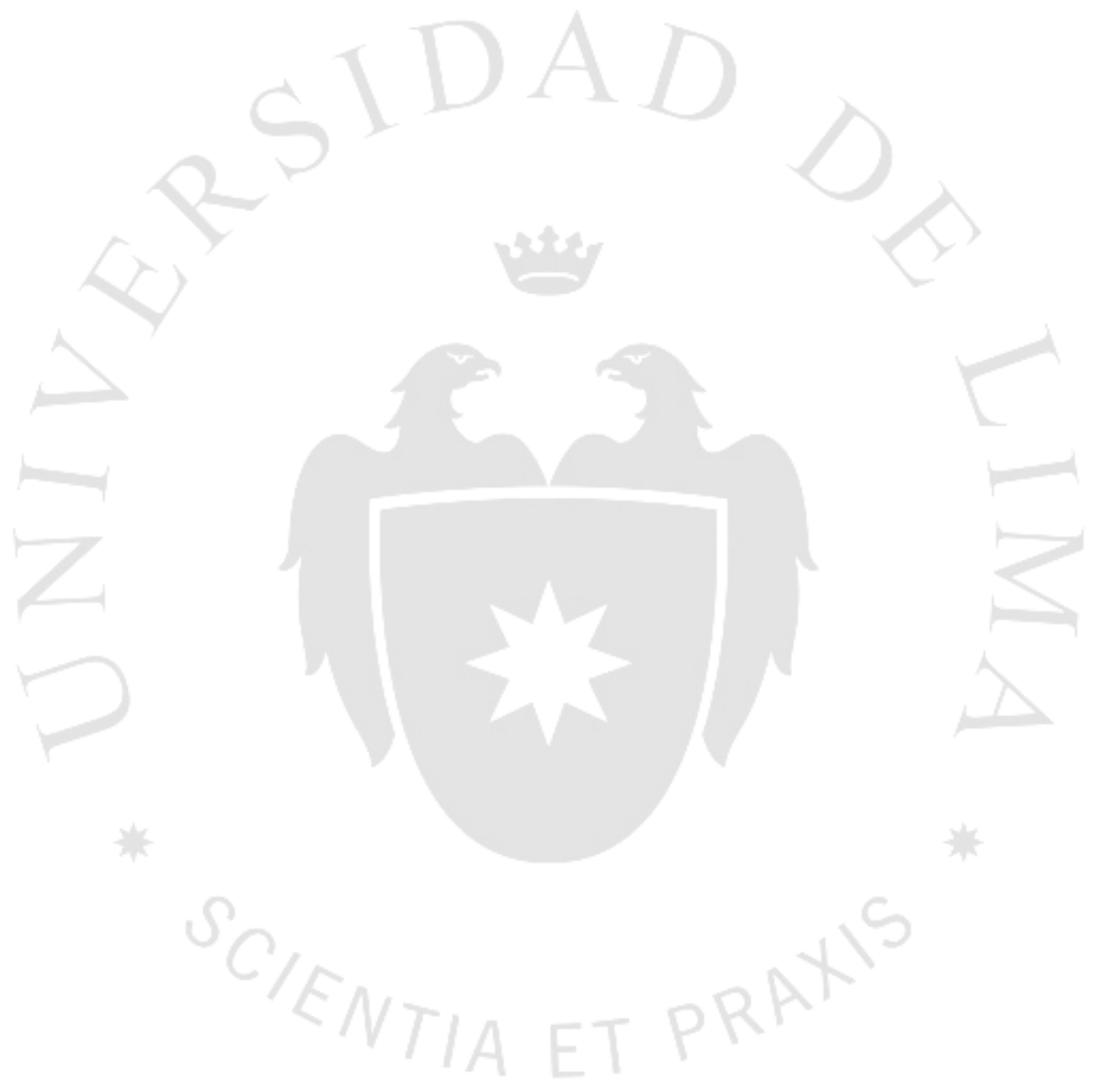




\section{INTRODUCCIÓN}

En los últimos años la búsqueda constante de sinergias y aprovechamiento de las tecnologías de información en la gestión administrativa y financiera de las compañías, ha sido el común denominador en las corporaciones, en especial en las áreas de tesorería, las cuales no solo desarrollan funciones de administración de liquidez, sino que también cumplen una destacada función en la planificación y obtención de rentabilidad.

La centralización de las áreas de tesorería, fue uno de los primeros pasos que dio génesis al modelo de contrato de cash pooling (en lo sucesivo, cash pooling), pues a través de dicha centralización los tesoreros generales conocían las posiciones de cada compañía miembro del grupo, es decir tenían conocimiento de las compañías superavitarias y deficitarias en lo que a liquidez corresponde.

De otro lado, el dinámico mercado de productos financieros, que el sistema financiero local e internacional ofrece en la actualidad a las compañías, ha provocado que éstas tengan opciones variadas de financiamiento, a costes y condiciones cada vez más atractivas, como también ha impulsado que tales compañías evalúen y exploren alternativas de endeudamiento no solo a nivel individual, sino corporativo.

El contrato de cash pooling, -materia de estudio en el presente trabajo- supone una combinación de los supuestos planteados en los párrafos anteriores, pues al manejo centralizado de la tesorería de los grupos empresariales, se suma la oferta por parte de las entidades financieras. Es así que la actuación del banco o pooler dentro de las organizaciones, consiste en recolocar los sobrantes de aquellas compañías superavitarias, en aquellas cuya posición requiera la inyección de liquidez -como una figura de endeudamiento indirecto-, devengando intereses de acuerdo a las posiciones ya mencionadas, a partir de la creación de una cuenta común para el grupo empresarial y cuentas individuales para las filiales partícipes.

Expuesto ello, corresponde advertir sobre los efectos o implicancias fiscales de este modelo de contrato. Como fue mencionado, el modelo de contrato de cash pooling a estudiar, es aquel en el que la entidad financiera no domiciliada actúa como pooler, y efectúa la colocación de los fondos en una compañía local domiciliada, la misma que 
paga intereses en favor de la entidad financiera, y registra el gasto financiero para sí misma. Si bien, tales gastos son deducibles para la determinación de la renta neta de tercera categoría, en la medida que se acredite su causalidad con la generación de rentas, éstas podrían ser cuestionadas cuantitativamente bajo la regla de subcapitalización prescrita en el artículo 37.a) de la ley del impuesto a la renta (en lo sucesivo LIR o Ley del IR), en caso se determine que tal regla resulta aplicable.

En ese sentido, el tratamiento tributario de los gastos financieros registrados por la compañía local, visto desde la regla de subcapitalización, es el tema de análisis y controversia en la presente trabajo, dado que la LIR ha establecido una regla de subcapitalización, que resulta de aplicación cuando concurren: (i) una operación de crédito o endeudamiento, y (ii) la actuación de compañías vinculadas, a diferencia de la regla de retención del impuesto a la renta (IR) prescrita en el artículo 56.j) de la LIR, que prescribió supuestos como el endeudamiento encubierto o back to back. Está situación pone en manifiesto una diferencia marcada entre ésta última regla y la de subcapitalización, e incertidumbre para la compañía local, sobre la aplicabilidad de la norma de subcapitalización.

A efectos de un entendimiento ordenado del presente trabajo, el mismo se ha divido en cuatro (4) capítulos; Capítulo I: Acercamiento a los contratos de cash pooling, Capítulo II: La regla de subcapitalización, y su inclusión en la ley del impuesto a la renta y la legislación comparada, Capítulo III: Interpretación de las normas tributarias en el Perú, y Capítulo IV: Aplicación de la regla de subcapitalización, en el marco de los contratos de cash pooling.

Por lo expuesto, son los objetivos del presente trabajo de investigación, definir el contrato del cash pooling, analizar la regla de subcapitalización desde la doctrina, y su establecimiento en nuestra legislación, repasar los principios y métodos de interpretación del derecho, ensayar una interpretación de la regla de subcapitalización en el marco de los contratos de cash pooling, y finalmente, determinar la aplicación de la regla de subcapitalización en los referidos contratos. 


\section{CAPÍTULO I: ACERCAMIENTO A LOS CONTRATOS DE CASH POOLING}

Los contratos de cash pooling, al igual que otros modelos de financiamiento desarrollados por las propias corporaciones y las entidades financieras, son sin duda, el reflejo del cambiante mundo financiero y empresarial, frente a los cuales en repetidas oportunidades, las normas en general, parecieren quedar desfasadas, o en todo caso, su interpretación y aplicación se ve restringida. Con el objeto de tener un entendimiento amplio y legal de este tipo de contrato, a continuación se procederá a detallar, lo que la doctrina ha desarrollado sobre el mismo.

\subsection{Conceptualización de los contratos de cash pooling}

La limitada difusión y aplicación en el Perú de este modelo de contrato financiero, explica el escaso estudio e investigación que tuvo éste en la legislación, doctrina y jurisprudencia local. Sin embargo, en países como los Estados Unidos, o europeos; su aplicación y estudio ha sido más difundido.

En principio, viene al caso señalar que el termino ingles "cash pooling”, tiene la acepción en el idioma español, como "cuenta mancomunada". Ello se explica debido a que la principal característica de este contrato es el establecimiento de una cuenta global centralizada para el grupo empresarial, conformada en paralelo por cuentas creadas para cada filial participe.

Como aproximación, el contrato de cash pooling podría ser definido como un instrumento financiero para la centralización de la tesorería mediante el cual las compañías o las corporaciones, en lugar de tener diversas líneas de crédito o cuentas bancarias (dependiendo de la posición del participe) tendrán una única cuenta, cuyo propósito es la reducción de costos de financiación, y una mejor posición al momento de negociar las condiciones con una entidad financiera.

De acuerdo a Serrano: El cash pooling es una herramienta financiera que permite transferir saldos y movimientos de cuentas bancarias pertenecientes a empresas 
vinculadas a un grupo, con el objetivo de dotarse de liquidez sin necesidad de formalizar contratos de préstamo. (Serrano Olivares, 2014, pág. 7)

De otro lado, Fuentes lo define como un sistema de gestión centralizada de la tesorería (cash managment) que suele adoptarse en los grupos de sociedades, el cual les permite llevar una estrategia financiera común y coordinada. (Fuentes, 2014, págs. 233266)

Barriocanal señala que sin duda el origen de estos modelos de contratos financieros, tiene que ver con los factores que la modernidad pone a disposición de toda Compañía, como son el avance tecnológico, la homogeneización de las comunicaciones bancarias y la profesionalización de las áreas de tesorería. Pues tales factores permiten la realización de la comunicación, y la participación de las filiales participes establecidas en diversos países. (Barriocanal Muñoz de la Espada, 2011, págs. 42-46)

En Norteamérica Leander lo conceptualiza como una técnica utilizada por los tesoreros, que consiste en agregarse los saldos de caja excedentes a través de diferentes cuentas con el fin de optimizar los intereses devengados y para gestionar mejor la liquidez. (Leander, 2015, págs. 30-31). Mientras que en Europa Szlęzak señala que se trata de una cuenta conjunta del grupo de empresas, que permite la compensación de transición fondos excedentes de una empresa con déficit de otra. (Szlęzak-Matusewicz, 2014, págs. 977-987)

En ese sentido, a modo de conclusión se puede señalar que el contrato de cash pooling, es un instrumento o acuerdo financiero, en el que participan las empresas pertenecientes a un grupo empresarial y una entidad bancaria (de ser el caso, o un pooler miembro de la misma corporación), mediante el cual ésta última toma los fondos de la compañías superavitarias en liquidez, y los coloca en aquellas compañías con déficit de liquides, en ambos casos las operaciones de captación y colocación, generar ingresos y gastos financieros de acuerdo a la posición de la compañía participe, todo ello a partir de la creación y administración de una cuenta única centralizada para el grupo y cuentas periféricas para las filiales.

\subsection{Ventajas, objetivos, y desventajas del contrato de cash pooling}

Las ventajas y objetivos de este tipo de contrato financiero se encuentran enfocados principalmente en dos aspectos; el ahorro en costes económicos y financieros, y las 
ventajas de orden y gestión administrativo en las áreas de tesorería. A continuación alguna de las ventajas y objetivos sobre este tipo de contratos, así como algunas desventajas:

\subsubsection{Ahorro en costes financieros y ventajas económicas:}

- Reducir el endeudamiento externo o fuera del grupo, tomando en consideración los costos y las formalidades que significan los contratos de financiamiento.

- La sociedad pooler se encuentra en posición de gestionar de forma más óptima los flujos de liquidez provenientes de las distintas sociedades del grupo, concediendo financiación a intereses convenientes, a las otras filiales del grupo. (Fuentes, 2014, págs. 233-266)

- Reduce el riesgo de tener cuentas corrientes del grupo en déficit, como también evita los excesos de liquidez, como afirma Fuentes. Es común observar que una de las principales operaciones intecompany son los préstamos directos, desde las filiales con saldo de caja suficientes hacia filiales sin esta ventaja, sin embargo si se toma en consideración los tiempos de comunicación, la frecuencia de las operaciones y los importes de los créditos, resulta evidente que siempre existirán compañías con exceso de liquidez, en consecuencia liquidez oficiosa, en comparación de otras con costes financieros elevados por la necesidad y oportunidad en que las filiales deficitarias en liquidez, las obtienen. (Fuentes, 2014, págs. 233-266)

- Reducción de saldos ociosos al reducirse el número de cuentas bancarias y de bancos a nivel grupo (Barriocanal Muñoz de la Espada, 2011, págs. 42-46).

- Mejor imagen bancaria del grupo, cuyas consecuencias deben ser aprovechadas en la negociación.

- Mayor capacidad de maniobra financiera, que permite controlar la liquidez inmediata del grupo y utilizarla en caso necesario. 


\subsubsection{Ventajas Administrativas}

- Disponer de una única solución global multibancaria que se sitúe por encima de las infraestructuras locales o regionales (Barriocanal Muñoz de la Espada, 2011). En los grupos o conglomerados empresariales las posiciones administrativas en lo que a distribución de personal se refiere, suelen estar establecidas de forma vertical, es decir un tesorero para la una región específica, o la posición de C.F.O. ${ }^{1}$ para un grupo de países, y no uno para cada país, lo que hace que un contrato de cash pooling sea acomode a dichas posiciones, o formas de organización.

- Supresión de instrumentos de financiación locales para ser reemplazados por instrumentos de crédito globales. (Barriocanal Muñoz de la Espada, 2011, págs. 42-46) Evidentemente suele ser más beneficiosa en términos de costes financieros, una negociación global o grupal, que una negociación individual local.

- Ahorro de costes en sistemas de información, procesos y herramientas de gestión en general.

\subsubsection{Desventajas de la implementación}

- Se deben ponderar los aspectos jurídicos y fiscales. En cada jurisdicción donde se encuentra las filiales o Compañías participes, se deberá observar las implicancias y efectos fiscales de acorde a la posición financiera.

- Mayores costes en la estructura central, correspondientes a los sistemas informáticos y de implantación del proyecto, así como mayores costes derivados de la centralización de los servicios bancarios, inherentes a la propia centralización del servicio y del tratamiento de los apuntes. (Barriocanal Muñoz de la Espada, 2011). El número limitado de entidades financieras especializadas en este tipo de contratos, explica los costes administrativos elevados y comisiones. Esto conlleva a deducir que estas operaciones serán convenientes en grupos de empresas con presencia e importes de facturación importantes.

${ }^{1}$ Chief Financial Officer o Director Financiero de una Compañía. 
- Problemas de disponibilidad ocasional de fondos en las cuentas periféricas. Esta situación suele presentarse en el contrato de cash pooling tipo balance cero, puesto que el barrido es realizado a una fecha preestablecida dejando reducida la posibilidad o margen de maniobra en situaciones específicas.

\subsection{Tipos de Contratos de Cash Pooling}

Desde la perspectiva de los objetivos que persiguen las Compañías, se pueden distinguir dos tipos de contratos:

- Cash Pooling Financiero.- Diseñada para objetivos como la gestión de liquidez, cobertura de necesidades, riesgos financieros (i.e. tipo de cambio, tipo de interés), optimización de excedentes de tesorería y negociación de condiciones bancarias óptimas. (AFI, 2009, págs. 1-6)

- Cash Pooling Operativo.- Diseñada para las funciones de planificación, previsión y realización de cobros, pagos y control de condiciones bancarias, además de las anteriores. (AFI, 2009, págs. 1-6)

Desde la perspectiva técnica, existen dos tipos de contratos claramente demarcados, el Cash Pooling de Balance Cero y Cash Pooling Nocional o Virtual; el primero en él que se ejecutan los "barridos" de efectivo, que significan dejar en cero los saldos de las cuentas de las compañías filiales participes, estén éstos con saldo de efectivo positivos o negativos, con un corte o dead line definido en los acuerdos, tomando los saldos positivos y cubriendo las obligaciones de los partícipes con déficit de liquidez.

Mientras que en el otro extremo se encuentra el cash pooling nocional, en el cual no se realizan transferencias o movimientos de efectivo, sino se toman o captan las posiciones de cada filial participe, permitiendo mostrar una posición bancaría como grupo, y determinando un posición neta, sobre ésta última se procede con el cálculo de intereses previamente acordados de acuerdo según corresponda. A continuación las principales características de los tipos de contratos.

\subsubsection{Cash Pooling de Balance Cero (ZBA):}

Zero balance system o zero assets, sistema en el cual en cada filial se calcula el saldo a final de día (o en una fecha establecida) y se ordena, antes de un límite horario, se 
proceden con las transferencias para bien enviar los fondos a la cuenta local de la entidad financiera, o bien recibir de esa cuenta los fondos necesarios para paliar las necesidades de tesorería.

De acuerdo a Barriocanal, el objetivo del cash pooling ZBA es saldar sistemáticamente las cuentas de las filiales en beneficio de una cuenta centralizadora de la matriz. Esta solución presenta la ventaja de su simplicidad y disminuir el coste del servicio de tesorería en el seno de las filiales. (Barriocanal Muñoz de la Espada, 2011, págs. 42-46)

Asimismo, Fuentes describe que este tipo de contrato funciona con transferencias efectivas de fondos, de los excedentes de cada una de las cuentas periféricas a la centralizada, en el seno de este sistema, en función de las obligaciones a las que normalmente tiene que atender las entidades participantes (Fuentes, 2014, págs. 233266). Szlęzak conceptualiza como una forma real de la financiación intragrupo, anticipa un flujo físico de dinero en efectivo en la cuenta maestra del grupo de empresas de las cuentas individuales y luego la asignación de esos fondos entre las cuentas de las empresas que requieren cofinanciación, estas transferencias de fondos por lo general se llevan a cabo al final del día que los montos podrían regresar en las cuentas de sus propietarios el día siguiente por la mañana. (Szlęzak-Matusewicz, 2014, págs. 977-987)

Mediante la adopción de este sistema la cuenta corriente que maneja la sociedad pooler, desarrolla un papel preponderante en las necesidades de financiación del resto de filiales, reflejándose como una línea de crédito a disposición de todos los miembros del grupo.

\subsubsection{Cash Pooling Nocional o Virtual:}

En este caso Barriocanal señala:

Que a entidad financiera suma por un lado todos los saldos acreedores y por otro los deudores, calcula qué porcentaje de saldos deudores están compensados con los saldos acreedores o viceversa y, en función de ese porcentaje, liquida a final de mes unos intereses a unos tipos (acreedores y deudores) negociados previamente. La empresa matriz puede incluso elegir la cantidad de intereses deudores o acreedores que aplica a cada filial participante en el pool, independientemente de la cifra de intereses que la 
entidad financiera esté aplicando en realidad, bajo una figura de "reasignación de intereses”. (Barriocanal Muñoz de la Espada, 2011, págs. 42-46)

Desde otro punto de vista, Fuentes también puede ser conceptualizado como aquel modelo en el que no se produce una transferencia material de los fondos de las cuentas periféricas a la cuenta centralizada, sino meros apuntes contables (habitualmente acompañados de garantías sobre la cobertura del desbalance). (Fuentes, 2014, págs. 233266). Para Miola, esta técnica es utilizada por el mundo anglosajón y que tiene como principal ventaja la racionalización de las relaciones del conjunto del grupo con el sistema bancario. (Miola, 2011, pág. 41)

En ese sentido, de acuerdo a Szlęzak, en este tipo de contrato no hay flujo de caja real entre cuentas de las empresas del grupo empresarial, únicamente se fijan las tasas de interés preferencial en déficit de caja y los excedentes, en consecuencia la entidad con un déficit de la balanza paga tasas de interés más bajas en comparación con las tasas de interés estándar a crédito en la cuenta corriente, mientras que la entidad con un balance positivo tiene una oportunidad de obtener una tasa de interés más alta en comparación con la ganancia resultante de un depósito de corto plazo. (Szlęzak-Matusewicz, 2014, págs. 977-987)

Como se observa que este segundo modelo de contrato de cash poling, está enfocado principalmente a la posición centralizada del grupo empresarial frente a la entidad o entidades financieras, puesto que en la cuentas periféricas de las filiales participes, no se realizaran trasvases efectivos de fondos, sino solo se consolidaran las posiciones deudoras y acreedoras en la cuenta master del grupo, y en función de esta se liquidaran los intereses, que evidentemente no serán meramente acreedoras, es decir intereses en favor únicamente del pooler o banco, sino que se verán reducidas por las posiciones deudoras de las filiales con excedentes de liquidez en el dead line.

A efectos de la presente investigación y como fue señalado la parte introductoria, más allá del tipo de contrato, es materia de estudio los efectos fiscales de los gastos financieros por intereses de una Compañía local domiciliada, y la renta obtenida por el banco no domiciliado.

\subsection{Naturaleza jurídica}


Como se advirtió en la parte inicial, no existen definiciones en la doctrina local, ni legislación sobre el tema, motivo por el cual realizaremos en paralelo en el análisis jurídico de este contrato en la doctrina y legislación comparada y un símil en el la doctrina local. Sin perjuicio de ellos, el análisis se encuentra enfocado en asignar una categoría jurídica a partir de la legislación civil, en ausencia de una definición propia en la legislación tributaria.

\subsubsection{De acuerdo a la legislación y doctrina comparada.}

En España se advierte que la posición común en la doctrina, es que se trata de un contrato atípico, motivo por el cual resulta dificultoso la determinación o asignación en una u otro categoría jurídica, más bien se señala que su naturaleza jurídica es mixta, al estar constituida de elementos de un contrato de cuenta corriente mercantil y un contrato de financiación o préstamo. (Fuentes, 2014, págs. 233-266)

Al igual que en la doctrina Alemana, en la doctrina Española existe una posición mayoritaria en determinar que los saldos activos de las cuentas periféricas a la centralización, representan el nacimiento de un derecho de crédito para las filiales, y por otro lado la cobertura del saldo pasivo de las otras cuentas periféricas, constituyen negocios de préstamos para las filiales correspondiente. Sin embargo la enmarcación del cash pooling dentro de la figura jurídica de contrato de préstamo no resulta completa, puesto que posee elementos de la figura de jurídica del contrato de cuenta corriente, como lo señala la doctrina en el caso español, puesto que en la práctica se tratan de aperturas y administración de cuentas en una entidades bancarias, claro está con objetivos financieros distintos a los de las cuenta corriente tradicional. (Altmeppen, 2010, pág. 401)

Lo descrito en el párrafo anterior se resume en que los traspasos positivos y negativos realizados hacia la sociedad pooler tienen la condición de préstamos (Ortega, 2005). La función de financiación ha sido confirmada también en Italia, tanto en la doctrina (Ruggeri, 2011, págs. 1-10) como en la jurisprudencia. 


\subsubsection{El símil en la legislación y doctrina local}

Ante la evidente ausencia de literatura sobre el modelo de contrato materia de estudio en la legislación y doctrina tributaria local, se debe buscar en la legislación civil, al igual que en el caso español, una categorización jurídica.

En nuestro país el contrato de préstamo o financiación se encuentra recogido en el artículo $1648^{2}$ del Código Civil, bajo la figura de "mutuo", sin embargo no existen mayores alcances sobre el contrato de cuenta corriente, situación que limita la enmarcación dentro de una categoría jurídica específica, más allá de la señalada. La definición en el caso español permite señalar que la categoría jurídica asignada no se encuentra alejada de una eventual definición en la doctrina local, a la luz de los evidentes rasgos que unen al contrato de cash pooling con el contrato de préstamo habitualmente utilizado.

Es de notar que en nuestra legislación tributaría, ni civil, se ha desarrollado o conceptualizado los modelos de contratos de cash pooling, como tampoco se existe referencias en la doctrina local. Evidentemente ello no será óbice para la eventual aplicación de normas tributarias y consecuencias, en caso sucedan o se configuren los hechos imponibles regulados, en este caso, por la Ley del IR.

En ese sentido, la consecuencia que interesa para efectos del presente trabajo, son los intereses registrados como gasto financiero por un sujeto domiciliado, provenientes del endeudamiento de un contrato de cash pooling, suscrito con sus pares vinculados no domiciliados, con la actuación de un pooler (entidad financiera) no domiciliado. En este caso, la norma que cobra relevancia es la de subcapitalización, y el límite impuesto para la deducibilidad de la renta neta. En el siguiente capítulo, se procederá a estudiar el fenómeno de la subcapitalización y su incorporación en la Ley del IR y la legislación comparada.

\footnotetext{
2 "Artículo 1648.- Por el mutuo, el mutuante se obliga a entregar al mutuatario una determinada cantidad de dinero o de bienes consumibles, a cambio de que se le devuelvan otros de la misma especie, calidad o cantidad".
} 


\section{CAPÍTULO II: LA REGLA DE SUBCAPITALIZACIÓN, Y SU INCLUSIÓN EN LA LEY DEL IMPUESTO A LA RENTA Y LA LEGISLACIÓN COMPARADA}

El desarrollo del presente capítulo se centrará en conceptualizar la regla de subcapitalización, determinar su naturaleza, y evaluar sus características. Con especial énfasis en las características del endeudamiento directo e indirecto, y la forma como han sido recogidas en la legislación local y legislación comparada.

\subsection{Definición y naturaleza de la regla de subcapitalización}

\subsubsection{Perspectiva societaria y financiera}

La subcapitalización consiste en disfrazar una aportación real de capital bajo la figura del préstamo, generando distorsiones en el ámbito jurídico-tributario como en el mercantil, considerando que las compañías tienen libertad de optar de financiamiento por medio de aportación de capital o endeudamiento. El concepto de subcapitalización debe ser analizado como la forma de financiación utilizada por las empresas de un mismo grupo económico, las cuales se encuentran integradas y bajo un control común, de acuerdo a Álvaro Blanco y Ángel Castro (Blanco \& Castro, 2010).

En la doctrina local, Montestruque ${ }^{3}$ señala:,

Se entiende por subcapitalización o infracapitalización de una sociedad, cuando la proporción entre el volumen de recursos propios y ajenos procedentes directa o indirectamente de sociedades del grupo, supera aquella proporción que podría considerarse normal en una situación de libre concurrencia. (Montestruque, 2006, págs. 255-271)

De otro lado, Palao señala que es la situación de una sociedad cuyo capital inferior al considerado como adecuado, lo cual sucede por carencia de recursos de recursos

\footnotetext{
${ }^{3}$ Abogada por la Universidad de Lima.
} 
financieros, o aunque los posea estos no constituyan fondos propios o capital, sino prestamos de los socios (Palao, 2012). O también considerada como una desproporción constatable entre la magnitud del capital de responsabilidad, fijada legal y estatutariamente, de acuerdo a la perspectiva de Cordón y Gutierrez (Cordón \& Gutiérrez, 2004).

\section{Según Blanco y Castro:}

La subcapitalización provoca un cambio en la estructura de la participación patrimonial y esto hace que se diluya el riesgo empresarial. Los socios son los que, aportando el capital, obtienen como beneficio societario por su aporte las utilidades si la empresa obtiene resultados positivos. En cambio, si lo que se coloca en la sociedad es aportación en calidad de préstamo, éste va a reclamar un rendimiento independientemente del resultado de la empresa. (Blanco \& Castro, 2010, págs. 1-26)

A modo de resumen podemos señalar que desde la perspectiva societaria y financiera, la subcapitalización es el fenómeno por el cual el financiamiento propio (vía aporte de capital), es significativamente inferior al financiamiento externo (vía préstamo) proveniente de los mismos propietarios. Tal fenómeno obedece al objetivo de reducción del riesgo empresarial, y consecuente obtención de rendimientos para el propietario más allá del resultado de la Compañía.

\subsubsection{Perspectiva fiscal}

De acuerdo a Palao, a subcapitalización interesa al Derecho Tributario en cuanto la financiación inadecuada de la sociedad por la vía del préstamo en lugar de capital propio, da lugar a la obtención de ventajas fiscales. Situación que cobra relevancia cuando tal operación supone la participación de entes ubicados en jurisdicciones fiscales distintas, en las cuales los tratamientos tributarios aplicables a cada operación, podrían desencadenar en la pérdida de recaudación en jurisdicción donde se produce el fenómeno de la subcapitalización. (Palao, 2012)

En el ámbito tributario, según Vega Borrero, el endeudamiento excesivo puede plantear problemas cuando quiénes financian una sociedad son sujetos con los que se encuentra vinculados, porque sus resultados pueden suponer un perjuicio recaudatorio para el Estado del prestamista, especialmente cuando los sujetos vinculados son no residentes, además de un quiebre de los principios que informan la tributación 
internacional y, particularmente, los que consagra el Modelo de convenio de la OCDE. (Vega Borrero, 2002, págs. 89-125)

Para Corona, la elección del financiamiento vía préstamo genera ventajas impositivas, como es la de deducir los intereses al calcular la base imponible del impuesto sobre sociedades, mientras que por contrario si la Compañía opta por la financiación propia, la retribución de los fondos propio no solo no tiene la consideración de partida deducible, sino que además podría generar problemas de imposición económica. (Corona, 1992)

De acuerdo a las posiciones de los autores expuestos, se puede resumir que desde la perspectiva fiscal, la infracapitalización o subcapitalización, supone el establecimiento de figuras tributarias anómalas, con el objeto de obtener ventajas fiscales a partir de reducir la renta imponible en la jurisdicción del prestamista, para eventualmente sujetarlos a imposición en una jurisdicción con una tasa inferior a la del país del prestatario.

\subsubsection{Métodos para evitar el fenómeno de la subcapitalización}

\section{- Método subjetivo}

De acuerdo a Vega Borrero, consiste en determinar si la sociedad disponía, en el momento de la concesión del préstamo, de la posibilidad de obtener de un tercero los mismos recursos aportados por el prestamista con el que se encuentra vinculado. Quedando la carga de la prueba en la Administración Tributaria, la que consistirá en constatar si la sociedad hubiera obtenido los mismos recursos bajos las mismas condiciones, de un sujeto independiente. (Vega Borrero, 2002, págs. 89-125)

\section{- Método objetivo}

El mismo autor señala que en este caso la norma tributaria establece un coeficiente máximo de endeudamiento, por comparación con el capital fiscal de la sociedad. La norma presume una vez superado el coeficiente de endeudamiento establecido la sociedad se encuentra subcapitalizada, siendo ésta método es el más empleado por los países. 


\subsubsection{Características de la regla de subcapitalización}

\section{- Situación de financiación anómala}

Como fue desarrollado en numerales anteriores, el factor principal que provoca la aplicación de la regla de subcapitalización, es la financiación inadecuada de las Compañías, que radica la financiación desproporcionada motivada en algunos casos por fines financieros y fiscales.

\section{- Operaciones entre vinculados}

De acuerdo Vega Borrero, los sujetos en sus transacciones deben operar como sujetos independientes, incluso cuando esas transacciones se producen entre sujetos vinculados. La existencia de vinculación entre las partes que intervienen en una transacción, puede hacer dudar que el valor de la misma no se ajuste con el que hubieran acordado de haberse realizado esa misma transacción entre partes independientes. Por este motivo, el art. 9 del Modelo OCDE autoriza a los Estados parte del convenio a realizar ajustes en las transacciones entre sujetos vinculados, cuando no respeten el principio de independencia. (Vega Borrero, 2002, págs. 89125)

El referido artículo 9 del Modelo OCDE, tiene por objeto garantizar que cada Estado pueda sujetar a tributación los beneficios realmente obtenidos en su territorio. Para evitar que ese beneficio pueda alterarse cuando las transacciones se realizan entre sujetos vinculados. Por lo tanto es este el marco en el que debe situarse las normas tributarias en materia de subcapitalización, porque solamente intervienen en transacciones entre sujetos vinculados. Cuando no existe vinculación, tanto el ordenamiento interno como internacional respeta el valor acordado por las partes, toda vez que al existir materialmente voluntades contrapuestas, no existe el riesgo de que las operaciones se manipulen con el fin reducir injustificadamente la carga fiscal., señala Vega Borrero.

$\mathrm{Al}$ respecto el mismo autor señala que subcapitalización debe entenderse en términos más restrictivos. No cualquier desproporción manifiesta entre recursos ajenos y propios es objeto de la norma tributaria sobre subcapitalización, 
sino solamente cuando el endeudamiento desproporcionado con sujetos con los que la entidad financiada se encuentra vinculada excede de su capacidad de crédito.

\section{- Financiación directa e indirecta, con intervención de partes vinculadas}

Uno de los aspectos más acuciantes de la regla de subcapitalización, es definir lo que debe entenderse por endeudamiento indirecto, lo que supone analizar a efectos de la presente investigación si es que los préstamos recibidos de entidades de crédito no vinculadas, con participación de empresas vinculadas, califican como financiamientos indirectos de empresas vinculadas. Figura representativa y similar al del modelo de contrato de cash pooling.

De acuerdo a Pita, en principio debe entenderse por endeudamiento directo al financiamiento por el cual el prestamista tiene derecho a la percepción del capital y los intereses. Los autores J. Rey y F. Collado (Rey \& Collado, 1993), Agregan que al concepto de endeudamiento directo debe incluirse toda operación de tipo financiero, como préstamos, créditos participativos y toda operación de tipo comercial. (Pita Grandal, 1998, págs. 11-22)

Para el Garcia Novoa ${ }^{4}$ existen dudas de si en el endeudamiento indirecto se incluyen los conocidos como prestamos back to back, operaciones próximas en la simulación negocial, en las cuales una entidad no vinculada normalmente una entidad de crédito, recibe unos fondos del prestamista ultimo del grupo, con la finalidad y el encargo de entregar fondos como préstamo a la entidad del grupo destinataria finalmente de esa financiación, como también existe la duda de si constituye endeudamiento indirecto cuando se trata de préstamos simplemente avalados o garantizados por el grupo o inclusive de líneas de crédito solidariamente a favor de diferentes compañías del grupo. (Garcia Novoa, 2010, págs. 1-41)

Mientras que para Delgado Pacheco, no caben dudas acerca de la inclusión dentro de ese llamado endeudamiento indirecto de los conocidos como préstamos back to back. Sin embargo, señala que más dificultades existen en la apreciación

\footnotetext{
${ }^{4}$ Catedrático de Derecho Tributario de la Universidad de Santiago de Compostela.
} 
de endeudamiento indirecto cuando se trata de préstamos simplemente avalados o garantizados por el grupo o inclusive de líneas de crédito solidariamente a favor de diferentes compañías del grupo. (Delgado Pacheco, 2005, págs. 97-118)

Al respecto Sanz Gadea, el endeudamiento indirecto es aquel que se contrae frente a residentes (vinculados o no) o frente a no vinculados (residentes o no), pero que por estar asociado a otra operación financiera produce el mismo efecto práctico que el endeudamiento directo. En este caso el endeudamiento indirecto se produce cuando el préstamo o crédito está respaldado por otra operación financiera de sentido inverso realizado por una entidad vinculada no residente. De manera complementaria, el mismo autor plantea que el endeudamiento indirecto se producirá en los préstamos y créditos respaldados con operaciones financieras asociadas (depósitos, garantías) concertadas con vinculadas no residentes. (Sanz Gadea, 2001)

Un típico ejemplo de este tipo de endeudamiento, lo constituyen los préstamos back to back, en los que un prestamista no residente concierta un deposito en un entidad financiera no vinculada que es quien, en una operación distinta y posterior, realiza el préstamo con el prestatarios final residente y que es una entidad vinculada con el primer prestamista del banco.

Según Müller y Wilke lo mencionado en el párrafo anterior, podría ser vista como la financiación ajena de la sociedad pagadora del interés ha sido concedida por un tercero (banco) y el socio de tal sociedad además tuvo que prestar garantías al tercero, lo que asegura la devolución del préstamo, por lo que en esta constelación, el tercero (banco) por un lado financia a la sociedad de capital que es pagadora del interés, y por el otro lado puede reclamar las garantías al socio de la sociedad, si ésta incumple con su deber de pago. (Niehus, Wilke, \& Müller, 2013, págs. 221-245)

Para Rey y Collado, debe entenderse por endeudamiento indirecto al que es realizado entre sujetos vinculados por intermedio de entidades interpuestas o intermediarias, Los autores exponen como ejemplo, los prestamos back to back, en los que un prestamista no residente concierta un depósito en una entidad financiera no vinculada que es quien en una operación distinta y posterior, realiza 
el préstamo con el prestatario final residente y que es una entidad vinculada con el primer prestamista de la cadena. (Rey \& Collado, 1993, págs. 80-97)

\subsection{Inclusión en la Ley el IR}

En nuestro país la regla de subcapitalización fue incorporada en la legislación a finales del año 2000, la misma que desde su inclusión no sufrió modificaciones significativas.

Es así que mediante Ley $\mathrm{N}^{\circ} 27356$ de fecha 17.10.2000, se incorporó a nuestra legislación la regla de subcapitalización, que posteriormente sería modificada por el Decreto Legislativo $\mathrm{N}^{\circ} 945$ de fecha 23.12.2003, con la variante que se muestra en los párrafos comparativos siguientes siguiente:

Ley $\mathrm{N}^{\circ} 27356$ (18.10.2000) (Vigente desde 01.01.2001 a 31.12.2003):

Último párrafo del artículo 37.a):

Serán deducibles los intereses provenientes de endeudamientos de contribuyentes con sujetos o empresas vinculadas cuando dicho endeudamiento no exceda del resultado de aplicar el coeficiente que se determine mediante decreto supremo sobre el patrimonio del contribuyente; los intereses que se obtengan por el exceso de endeudamiento que resulte de la aplicación del coeficiente no serán deducibles.

Decreto Supremo N 945 (23.12.03) (Vigente desde 01.01.2004 a la actualidad):

Quinto párrafo del artículo 37.a):

Serán deducibles los intereses provenientes de endeudamientos de contribuyentes con partes vinculadas ${ }^{5}$ cuando dicho endeudamiento no exceda del resultado de aplicar el coeficiente que se determine mediante decreto supremo sobre el patrimonio del contribuyente; los intereses que se obtengan por el exceso de endeudamiento que resulte de la aplicación del coeficiente no serán deducibles.

En lo que respecta a la norma reglamentaria, ésta fue incorporada por Decreto Supremo No 045-2001-EF de fecha 20.03.2001. Así el numeral 6 del artículo 21.a) del Reglamento de la LIR, a la letra prescribe lo siguiente:

\footnotetext{
${ }^{5} \mathrm{Al}$ respecto, la modificación de la frase:“(...) contribuyentes con sujetos o empresas vinculadas (...)” por "(...) contribuyentes con partes vinculadas (...)", obedeció a un criterio de uniformidad entre la regla de subcapitalización y las normas de precios de transferencia, puesto que éstas últimas sufrieron modificaciones en ese sentido, en específico el numeral 4 del artículo 32 de la LIR.
} 
El monto máximo de endeudamiento con sujetos o empresas vinculadas, a que se refiere el último párrafo del inciso a) del Artículo 37 de la Ley, se determinará aplicando un coeficiente de 3 (tres) al patrimonio neto del contribuyente al cierre del ejercicio anterior $[\ldots]$

Los contribuyentes que se constituyan en el ejercicio considerarán como patrimonio neto su patrimonio inicial.

$\mathrm{Si}$ en cualquier momento del ejercicio el endeudamiento con sujetos o empresas vinculadas excede el monto máximo determinado en el primer párrafo de este numeral, sólo serán deducibles los intereses que proporcionalmente correspondan a dicho monto máximo de endeudamiento. [...]"

Como se observa, la regla de subcapitalización prescrita en nuestra legislación no ha tenido modificaciones significativas desde su incorporación, a inicios de la década pasada. Tal situación ha conllevado a que la misma haya quedado relegada frente al desarrollo local e internacional de las formas de financiamiento de las compañías, resultando necesaria su adecuación ante el comentado desarrollo y la legislación comparada.

\subsection{Características de la Regla de Subcapitalización en la LIR}

A continuaciones algunas características de la regla de subcapitalización que se encuentra vigente:

\subsubsection{Adopción del método objetivo}

Montestruque, señala que la LIR al igual que otros países de la OCDE ha optado por el método objetivo, fijando un coeficiente fijo de recursos ajenos/recursos propios para permitir la deducibilidad de los intereses provenientes de una operación de endeudamiento entre entidades vinculadas. (Montestruque, 2006, págs. 255-271)

Como fue detallado en los métodos para evitar el fenómeno de la subcapitalización, el método objetivo consiste en fijar un coeficiente determinado, que 
para efectos de la legislación local es de 3 (tres) a 1 (uno). Respecto al ratio, la Administración Tributaria ${ }^{6}$ (SUNAT, 2002) ha señalado que

El cálculo de la proporcionalidad de los intereses deducibles deberá efectuarse a partir de la fecha en que el monto total de endeudamiento con sujetos o empresas vinculados supere el monto señalado en el numeral anterior y por el lapso en que se mantenga dicha situación.

Sobre la adopción del método objetivo, $\mathrm{Joo}^{7}$ ha señalado que éste vulnera el artículo $9^{\circ}$ del Modelo OCDE, puesto que estaría desconociendo el Principio de Libre Concurrencia. (Joo Garfias, 2008)

\subsubsection{Financiamiento con partes vinculadas}

La configuración del fenómeno de subcapitalización tendrá relevancia fiscal en la medida que sea realizada entre partes vinculadas, y más aún si el financista es un sujeto no domiciliado en el país.

Con relación a este requisito, cabe señalar que la definición de partes vinculadas la encontramos en el artículo 32-A de la LIR, el mismo que contempla tres supuestos de vinculación económica relacionados con el control, administración o capital entre dos o más personas, empresas o entidades. La definición de partes vinculadas se encuentra en el artículo 24 del reglamento de la LIR.

\subsubsection{Endeudamiento directo e indirecto}

Como se observa, la norma se ha limitado a prescribir el supuesto de endeudamiento entre partes vinculadas, sin hacer la especificación si ésta abarca los supuestos de endeudamiento directo e indirecto.

Al respecto, Montestruque haciendo referencia a la situación teórica de la regla, ha señalado:

Hemos dicho también que el endeudamiento puede ser directo o indirecto. El primero no ofrece, por obvio, mayor comentario. Sin embargo, en cuanto al endeudamiento indirecto

\footnotetext{
${ }^{6}$ El Informe $\mathrm{N}^{\circ}$ 005-2002-SUNAT/K00000, es el único pronunciamiento respecto de la regla de subcapitalización, por parte de la Administración Tributaria.

${ }^{7}$ Abogado por la Universidad Peruana de Ciencias Aplicadas.
} 
se presentan algunos problemas de interpretación por la falta de precisión de los conceptos empleados., (Montestruque, 2006, págs. 255-271)

Sin embargo, la misma autora en referencia a la regla impuesta en nuestra legislación, afirma:

Respecto del segundo requisito cabe notar que nuestra LIR se refiere únicamente a "endeudamiento" sin distinguir si el mismo debe ser uno directo o indirecto. No obstante, entendemos que puede configurarse cualquiera de dichos supuestos a fin de que sea aplicable la norma bajo comentario. En todo caso, consideramos que el endeudamiento indirecto está comprendido al darse la posibilidad de que existan supuestos de vinculación a través de sujetos interpuestos. (Subrayado agregado).

Asimismo, Chevarría, considera que la eficacia de la norma de subcapitalización en nuestro país reposará en la inclusión del presupuesto de hecho de la norma del endeudamiento indirecto (como propuesta de mejora legislativa). (Chevarría Arrieta, 2009)

De otro lado, Esquives Espinoza ${ }^{8}$ señala que:

[...] En el caso peruano se ha establecido que la proporción entre capitales propios y ajenos sea de tres a uno para que se pueda deducir la totalidad de intereses; si la proporción más razonable es difícil de discutir, pero lo que si amerita reflexionar es si corresponde que dicho tratamiento sea aplicable para todo tipo de operaciones y empresas.

Por ejemplo, es conocido que se obtienen un mayor ahorro en las negociaciones de cualquier producto a gran escala, y en el caso de la obtención de fondos ocurre lo mismo. Es por ello que muchas empresas multinacionales obtienen directamente financiamiento de un Banco independiente para todas sus subsidiarias, a las cuales les traslada el interés que a su vez tiene que pagar, es decir, la matriz solo requiere el reembolso del gasto. De acuerdo a la doctrina, en estas operaciones se verificaría sin problema que el precio es de plena competencia si sustenta que el interés pagado por la subsidiaria a la matriz es para que éste a su vez pague a un tercero. Asimismo, también podría entenderse ello si la matriz aplica un margen de beneficio que refleje de manera razonable los costes en los que ha incurrido para obtener ese crédito. Cabe resaltar que resulta razonable, ya que en tales casos la matriz gestiona la financiación de todo el grupo, y con ellos obtiene mejores condiciones de las que podría obtener cada subsidiaria por separado. Ahora bien, de

\footnotetext{
${ }^{8}$ Abogado de la Pontificia Universidad Católica del Perú.
} 
acuerdo a la norma bajo comentario, en el Perú no se analizaría si los fondos obtenidos por la subsidiaria peruana a través de este mecanismo la eximirían de la limitación de intereses por subcapitalización." (Esquives Espinoza, 2012) (Subrayado agregado).

Sustentando su argumento final en una sentencia del Tribunal Económico Administrativo Central de España del año 2004, que señala:

Solo tienen deducibilidad los intereses imputados por la $\mathrm{CC}^{9}$ cuando se pueda demostrar la relación directa y univoca entre los préstamos contraídos por la CC y las necesidades del $\mathrm{EP}^{10}$, esto es: los intereses pagados a terceros pagados por la $\mathrm{CC}$ y trasladados a su EP en función de los capitales utilizados por dicho EP”

Como se observa, los autores desde perspectivas distintas, las primeras, tributaria y legal, y la segunda vista desde el punto de vista de las Normas de Precios de Transferencia, evidencian los problemas de interpretación en la redacción de la norma. Para Karina Montestruque la regla de subcapitalización peruana resulta de aplicación incluso para los supuestos endeudamiento indirecto, mientras que para Zully Chevarría dicho supuestos no se encuentra incluido, tanto así que propone su inclusión. En el caso de Ramón Esquives, señala que operaciones similares a los contratos de cash pooling, se eximirían de dicho tratamiento, ya que ante todo primaria la verificación del Principio de Libre Concurrencia.

\subsection{Tratamiento en la legislación comparada}

Dada la implicancia en la fiscalidad internacional de la regla de subcapitalización, resulta necesaria la revisión de la legislación, jurisprudencia y doctrina comparada, con el objeto de realizar un análisis en paralelo de nuestra legislación.

\subsubsection{El caso español}

En la legislación española ${ }^{11}$ ha establecido la regla de subcapitalización siguiente:

\footnotetext{
${ }^{9}$ Casa central o, casa matriz.

${ }^{10}$ Establecimiento permanente.

${ }^{11}$ Artículo 20 de la Ley del impuesto sobre las sociedades.
} 
[...] el endeudamiento neto remunerado, directo o indirecto, de una entidad, [...] con otra u otras personas o entidades no residentes en territorio español con a las que está vinculada, exceda del resultado de aplicar el coeficiente 3 a la cifra de capital fiscal [...]

A diferencia de la norma peruana, se observa que en España se ha considerado expresamente los conceptos de endeudamiento directo e indirecto.

Asimismo, la Dirección General de Tributos mediante la Resolución 1210-01 de fecha 20/06/2001, ha sostenido que el endeudamiento indirecto comprende los préstamos avalados o garantizados por una entidad vinculada y no residente, sin embargo, exige que la Administración Tributaria Española deba probar que la entidad no residente avalista o garante está obligada a hacer frente al pago del préstamo, o que la entidad prestataria residente no habría obtenido en condiciones normales de mercado tales garantías, que le hubieran permitido lograr esa financiación de un tercero independiente. Esas garantías han de ser formales, extendiendo el riesgo al avalista o garante vinculado y no residente, no bastando la mera confianza que da al prestamista la pertenencia del prestatario residente a un determinado grupo empresarial.

En otra consulta ( $\mathrm{N}^{\circ}$ 0503-98 de 30 de marzo), la Dirección General de Tributos manifestó el endeudamiento indirecto también incluye aquella situación en la cual la entidad no residente vinculada, si bien no es prestamista, en última instancia asume el riesgo derivado de la posible insolvencia del deudor, lo que sólo podrá ser constatado considerando el conjunto de circunstancias de cada supuesto: estructura financiera de la entidad prestataria, situaciones en que deba hacerse efectivo el aval, posibilidad de que finalmente se incurra en insolvencia. Mientras que en la consulta $\mathrm{N}^{\circ} 1210-01$ sostuvo en el caso consultado, en el que la entidad vinculada no residente no ofrecería garantías formales y concretas, con fuerza ejecutiva, sino tan sólo la confianza generada por el volumen y la solvencia demostrados hasta ese momento, la posible insolvencia del deudor residente no queda jurídicamente cubierta por aquella, por lo que no cabría hablar de endeudamiento indirecto con él.

La jurisprudencia también se ha manifestado sobre el particular, como es el caso de la Resolución $N^{\circ}$ 1825/2011 del Tribunal Supremo. Caso en el cual se trata de dilucidar la existencia o no de la figura de endeudamiento indirecto, en la cual la matriz expresa su compromiso de no vender ni disponer del capital social de la subsidiaria, y por la cual ofrece su respaldo en la operación de préstamo. A través de una carta de seguridad o letter of comfort. 
En esta resolución si bien no se establece o ensaya una conceptualización del endeudamiento indirecto, se señala que sólo cuando la Administración acredite que se produce o se va a producir la base y razón de ser de la norma de subcapitalización, que no es otra que la elusión fiscal mediante la erosión de las bases tributarias españolas a favor de otra entidad del mismo grupo y no residente en España, es cuando adquiere sentido la aplicación del artículo 16.9 (ahora artículo 20) Nada de ello hace la Administración Tributaria, sometiéndose la Sala de instancia a una actuación que en sí mismo encerraba una auténtica petición de principio, cuál era la presencia de un endeudamiento indirecto de los contemplados en el artículo 20 sin más justificación.

Lo expresado en la resolución resulta de importancia, puesto que pone en manifiesto los fundamentos de la norma que subcapitalización y los motivos de su inclusión en la legislación. La elusión fiscal es el objeto de la implantación de esta norma, y el Tribunal Supremo de manera correcta en mi opinión, pone como primer elemento de prueba del fenómeno de subcapitalización la determinación del perjuicio fiscal o erosión de las base imponibles en el estado donde se alocan los gastos financieros, antes de evaluar la existencia del endeudamiento indirecto propiamente.

Respecto de la legislación y pronunciamientos de la Dirección General de Tributos, se puede afirmar que norma española ha establecido una regla de subcapitalización más completa, en el extremo referido al endeudamiento directo e indirecto, así como ha interpretado a través de la ya mencionada Dirección, los supuestos de endeudamiento indirecto, marcando un derrotero de lo que debe entenderse por dicha norma, en este caso incluyendo los supuestos de back to back y aquellos préstamos garantizados.

De otro lado la doctrina también ha sido participe de la interpretación expuesta en el párrafo anterior, como es el caso de los autores Garcia Novoa, Delgado Pacheco, Rey y Collado, entre otros; como fue desarrollado en el acápite referido a las características de la regla de subcapitalización.

\subsubsection{El caso colombiano}

El artículo 118-1 del Estatuto Tributario Nacional, señala:

[...] los contribuyentes del impuesto sobre la renta y complementarios sólo podrán deducir los intereses generados con ocasión de deudas, cuyo monto total promedio 
durante el correspondiente año gravable no exceda el resultado de multiplicar por tres (3) el patrimonio líquido $[\ldots]$

Castro ha señalado que en esta norma no se excluyen las operaciones internas ni las operaciones con entidades no vinculadas, a pesar de que la exposición de motivos del primer proyecto parecía orientar la norma solo a operaciones con partes relacionadas. Ello tiene como ventaja que las operaciones de financiación indirecta (back to back) y de garantías resultan inocuas para eludir la norma. (Castro Arango, 2013, págs. 161-190)

La norma establecida por la legislación colombiana resulta muy similar a la nuestra, en el aspecto del tipo de endeudamiento, puesto que no se ha definido si este incluye el directo e indirecto, lo que nos ubica en la misma deficiencia que ubicamos en la legislación peruana, como señala el autor.

Como se ha observado en el desarrollo del presente capítulo, llama la atención la forma como la regla de subcapitalización ha sido incorporada en nuestra legislación, por siguientes motivos:

i. No contempla supuestos de endeudamiento actuales, o en todo caso existirían algunos modelos de endeudamiento -como es el caso de contrato de cash poolingque sin necesidad de tener un fin elusivo, podrían devenir en irrealizables, dada la incertidumbre en su aplicación;

ii. Como señala la jurisprudencia española, para la interpretación y aplicación de la norma de subcapitalización, se deben observar los motivos de su inclusión como norma anti-elusiva.

iii. Tampoco ha observado la legislación, jurisprudencia y doctrina comparada, en las cuales se ha contemplado claramente supuestos de endeudamiento directo e indirecto.

Dado que el cuestionamiento principal del presente trabajo, es la aplicación de la regla de subcapitalización (artículo 37.a) de la Ley del IR) en los contratos de cash pooling, resulta de importancia realizar una lectura e interpretación adecuada de dicha norma, acorde a los métodos y principios de interpretación recogidos y permitidos en el campo del derecho en general y el derecho tributario, en ese sentido, procederemos a repasar tales métodos y principios, en el capítulo siguiente. 


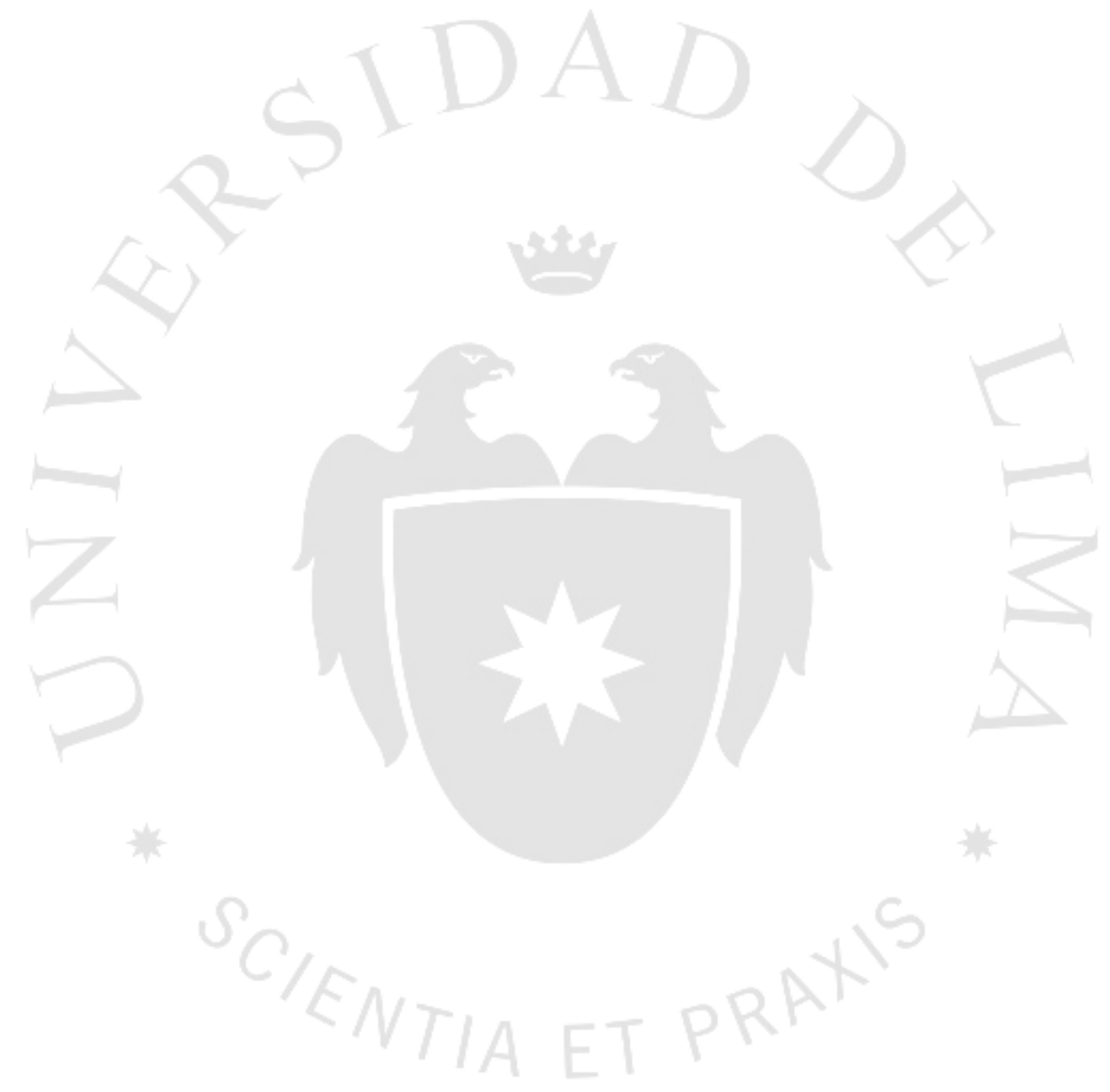




\section{CAPÍTULO III: INTERPRETACIÓN DE LAS NOMAS TRIBUTARIAS EN EL PERÚ}

En el presente capítulo repasaremos los principios y métodos de interpretación del derecho general y tributario, con el objeto de entender y ensayar una interpretación de la regla de subcapitalización redactada en la Ley del IR.

En ese sentido, nuestro ordenamiento jurídico - Código Tributario ${ }^{12}$ - ha definido los parámetros para la deducción o interpretación de las normas tributarias, los cuales se detallan a continuación:

\subsubsection{Normas del Código Tributario}

En nuestro ordenamiento jurídico, el Código Tributario ha previsto las normas siguientes para la interpretación de las normas tributarias:

\section{- Norma III: Fuentes del Derecho Tributario}

Son fuentes del Derecho Tributario:

a) Las disposiciones constitucionales; b) Los tratados internacionales aprobados por el Congreso y ratificados por el Presidente de la República; c) Las leyes tributarias y las normas de rango equivalente; d) Las leyes orgánicas o especiales que norman la creación de tributos regionales o municipales; e) Los decretos supremos y las normas reglamentarias; f) La jurisprudencia; g) Las resoluciones de carácter general emitidas por la Administración Tributaria; y, h) La doctrina jurídica.

- Norma VIII: Interpretación De Normas Tributarias

$\mathrm{Al}$ aplicar las normas tributarias podrá usarse todos los métodos de interpretación admitidos por el Derecho.

En vía de interpretación no podrá crearse tributos, establecerse sanciones, concederse exoneraciones, ni extenderse las disposiciones tributarias a personas o supuestos

${ }^{12}$ Aprobado por Decreto Supremo No 133-2013-EF. 
distintos de los señalados en la ley. Lo dispuesto en la Norma XVI no afecta lo señalado en el presente párrafo.

\section{- Norma IX: Aplicación Supletoria de los Principios del Derecho}

En lo no previsto por este Código o en otras normas tributarias podrán aplicarse normas distintas a las tributarias siempre que no se les opongan ni las desnaturalicen. Supletoriamente se aplicarán los Principios del Derecho Tributario, o en su defecto, los Principios del Derecho Administrativo y los Principios Generales del Derecho.

Como fluye de las normas expuestas, el Código Tributario ha previsto supuestos en los cuales la norma tributaria, por si misma, no resultará suficiente para su entendimiento y aplicación, en consecuencia serán de aplicación los métodos de interpretación del derecho, alguno de los cuales se procederán a detallar.

\subsection{Técnicas o métodos de interpretación del derecho}

A continuación se describirán los principales métodos y técnicas de interpretación del derecho en general y del derecho tributario:

\subsubsection{Técnicas o métodos de interpretación del derecho en general}

\section{- Método literal, gramatical o filológico}

De acuerdo a Du Pasquier este método consiste en deducir de las palabras mismas, de su lugar en la frase y de su sintaxis de la misma puntuación, en el sentido exacto del artículo de que se trata (Du Pasquier, 1983). Asimismo, Bullard respecto del método literal, afirma que en el fondo una reducción de la declaración contractual como todo lo interpretable, conduce a un textualismo asfixiante que olvida que las partes pueden haber acordado que no están realmente de acuerdo. (Bullard Gonzales, 2007)

Según Ausejo por este método se busca estudiar la letra de la ley, de lo que su texto quiere significar. Al mismo tiempo concluye que el método literal es la puerta de entrada a la interpretación dentro de cualquier sistema jurídico basado en la escritura. (Ausejo Gutiérrez, 2013) 


\section{- Método histórico}

Ausejo describe éste método como el estudio de las circunstancias en las que se dicta la norma, así como la motivación que tuvieron sus autores. (Ausejo Gutiérrez, 2013). De otro lado, Garcia Toma señala que entre las características de este método está la inclusión del espíritu histórico en el análisis de las instituciones, reconstruye el pensamiento contenido en la Ley, para lo cual el intérprete debe colocarse en lugar de legislador. Agrega éste último autor que el método histórico evolutivo además; defiende la finalidad de la Ley, busca afirmar determinados resultados morales, político o económicos que aparecen como deseables para la sociedad y la búsqueda constante de la intención del legislador. (Garcia Toma, 1995)

\section{- Método teleológico, finalista o casualista}

De acuerdo a éste método las leyes deben ser interpretadas según los fines para los cuales fueron establecidas, como señala Ausejo. Agrega que dicho método supone la búsqueda de la voluntad de la Ley (Ausejo Gutiérrez, 2013).

Al respecto Reale (Reale, 1984) señala que:

“toda interpretación jurídica es de naturaleza teleológica (finalistica) fundada en la consistencia axiológica (valorativa) del Derecho; toda interpretación jurídica ha de darse en el seno de una estructura de significaciones, y de no forma aislada, y cada precepto comporta la significación de algo que está situado en la totalidad del ordenamiento jurídico".

\section{- Método sistemático}

Messineo resalta sobre la utilidad tomar el elemento llamado sistemático, significa que no solamente los términos singulares se agrupan y se coordinan en proposiciones, es decir articulo o partes de artículos, sino que las proposiciones mismas se coordinan en organismos progresivamente más amplios, hasta constituir un entero cuerpo orgánico de normas vigentes. (Messineo, 1956) 
A su vez De Diego destaca que el elemento sistemático se apoya en la consideración de ser los elementos de la ley una parte de ella misma, como ésta es parte de un todo mayor que es el derecho positivo de un pueblo, y es natural que su sentido solo sea alcanzado en conjunto (De Diego, 1930). Añade el autor que éste método es una ampliación del método lógico.

Sobre el particular, Rubio divide este método en dos categorías (Rubio Correa, 1985):

\section{○ Método sistemático por comparación con otras normas}

Señala que éste método solo debe ser aplicado cuando se trata del análisis de normas generales entre sí, y no cuando se trata una combinación de normas especiales y generales, y menos aún entre nomas especiales entre sí. Esta subcategoría tiene lugar cuando lo que se busca es esclarecer el que quiere decir la norma jurídica, atribuyéndole principios y conceptos que quedan claros en otras normas del sistema jurídico y que no lo están en ellas.

\section{○ Método sistemático por ubicación de la norma}

El profesor Rubio señala que la interpretación debe hacerse teniendo en consideración el conjunto, sub conjunto, grupo normativo, etc., en el cual se encuentra incorporada. Explica que la razón de ser está en darle significado a la norma a partir del "medio ambiente", de su conjunto, sub conjunto, grupo normativo.

Finalmente Valencia destaca que éste tipo de interpretación permite prestar servicios al interprete cuando se encuentra frente a textos legales contradictorios, oscuros, insuficientes o cuando su escueta aplicación conduce al absurdo o engendra una solución manifiestamente inequitativa. Añade que un "juez debe escoger el sentido de uno de los textos con preferencia a otro, para destruir la contradicción, o dar claridad al oscuro, o completar el insuficiente, o inequitativo para hacer prevalecer los principios de la equidad". (Valencia Zea, 1981) 


\section{- Método lógico}

De acuerdo a Ausejo implica la descomposición del pensamiento o relación lógica que unen sus distintos componentes, es decir, se verifica un análisis material suministrado en el examen gramatical excavando en su estructura lógica. Para Marcial Rubio, la interpretación bajo éste método, supone el desentrañamiento de la razón de ser intrínseca del propio texto normativo. (Ausejo Gutiérrez, 2013)

\section{- Otros métodos}

La doctrina ha desarrollado diversos métodos de interpretación distintos a los expuestos en los desarrollados anteriormente, entre los cuales según Ausejo tenemos: El método sociológico, el método de la libre investigación científica, el método de la Escuela de Derecho Libre o movimiento de Freirecht, el método doctrinario, el método autentico o legislativo, el método de interpretación jurisprudencial, y los métodos según sus resultados o extensión. (Ausejo Gutiérrez, 2013)

De acuerdo a la conceptualización que cada autor desarrolla por cada método, se puede afirmar que, en el día a día de la interpretación, es decir, en nuestra labor diaria de intérpretes de la normas en general, desde nuestra posición de ciudadanos, usuarios, asesores, consultores, auditores, entre otros; en repetidas ocasiones utilizamos diversos aspectos de cada método interpretativo, con el fin de establecer cuando una norma resulta de aplicación sobre un supuesto especifico, o cuáles son sus alcances o limitaciones, y en otras, respetamos estrictamente los que la norma a la letra dice, como en el caso del método literal, cuando se revisan casos de requisitos de tramitología, por ejemplo.

\subsubsection{Principios de interpretación de la ley tributaria}

A continuación se describirán los principios que norman la interpretación de las leyes tributarias, que según Tarsitano, actúan a amanera de presupuestos que orientan al 
intérprete, y que posteriormente se concretan en métodos de interpretación (Tarsitano, 2003, págs. 411 - 459):

\section{- Voluntad de la ley y voluntad del legislador}

De acuerdo a Tarsitano (Tarsitano, 2003) citando a Vanoni señala que el primer problema de quien está a cargo de la interpretación, es el de saber que se entiende por sentido y por voluntad de la ley, para luego determinar mediante que vía puede individualizar dicho sentido y voluntad. El autor añade que para ello existen dos corrientes o teorías (Vanoni, 1973):

\section{○ Teoría Subjetiva}

Mediante esta corriente se identifica la voluntad de la ley con la voluntad del legislador, lo cual significa que la intención del legislador tiene la máxima importancia, y por ende los documentos previos a su aprobación y publicación, que en nuestra legislación serían los proyectos de ley, exposición de motivos, entre otros.

\section{○ Teoría Objetiva}

A diferencias de la corriente anterior, ésta señala que la ley se objetiva en las palabras, y que éstas adquieren vida propia desligada del espíritu de les dio origen.

Agrega el autor, citando a Ross (Ross) que la interpretación es subjetiva cuando se considera no solo a la expresión lingüística, sino otros aspectos relevantes como: el contexto, la situación, el propósito declarado y el presumido; mientras que la interpretación objetiva limita los datos que son discernibles por el destinatario en la situación en que se halla al aprehender la expresión. Finaliza que la diferencia depende de los datos que se toman en cuenta para interpretar.

\section{- Elementos para considerar la interpretación de la ley}

Alberto Tarsitano (Tarsitano, 2003) citando a Von Savigny (Savigny, 2009) identifica cuatro elementos que sirven de base a los criterios de interpretación: 
i) Elemento gramatical.- Referido al conocimiento de las palaras y al leguaje jurídico.

ii) Elemento lógico.- Relativo a la articulación de las reglas lógicas que configuran el pensamiento

iii) Elemento histórico.- Determinante de la identificación del cambio introducido en el derecho vigente al tiempo de la sanción de la ley que se interpreta.

iv) Elemento sistemático.- Como factor de unidad e interpretación de normas e instituciones dentro del derecho.

Señala Tarsitano que antes de constituir distintas clases de interpretación, dichos elementos, debían ser conjugados en el camino recorrido en el intérprete.

\section{- Jurisprudencia de conceptos y jurisprudencia de interés}

La jurisprudencia de conceptos tiene su génesis en Alemania, en el siglo XIX, señala Alberto Tarsitano (Tarsitano, 2003) citando a Gustavo Krause (Krause Murguiondo, 2000). Agrega que su propuesta consiste en construir una solución provista por las categorías conceptuales creadas por la Ley, que se relacionan entre sí. De acuerdo a esta corriente, el derecho configura un orden preciso y cerrado, en la cual se aprecian la teoría, los principios, los conceptos, y las instituciones abstraídas de la Ley, solo de manera contingente se valoran los intereses, mediante la Ley o en tanto se cristalicen en ella.

De otro lado, Tarsitano citando a Andrea Amatucci (Amatucci, 2001) sobre la jurisprudencia de intereses, destaca que ésta corriente extendió la interpretación a una captación más directa de los valores tutelados por las normas, sin la intermediación de las categoría conceptuales abstractas. Amatucci, señala que el ordenamiento jurídico está constituido por órdenes, que propenden al fin de organizar la vida, cuyas pretensiones serían los intereses, materiales e ideales. Asimismo, explica que la leyes deben garantizar la correcta tutela de tales intereses en favor de sus titulares, $\mathrm{y}$, teniendo en cuenta que no se trata solo de intereses materiales, sino también ideales y 
sociales, dicha teoría se ha convertido actualmente en una jurisprudencia de valores.

\section{- Los cánones hermenéuticos}

Betti señala que toda la dialéctica del proceso interpretativo surge de la antonimia entre la subjetividad del entender y la objetividad del sentido atribuido a la ley, y la antonimia la actualidad del sujeto y la alteridad del objeto, situación que da origen a la dialéctica de todo proceso cognoscitivo. (Betti, 1975)

Betti, afirma que los "cánones hermenéuticos fundamentales", elaborado en principio en las categorías civilistas, son admitidos como idóneos para gobernar la interpretación en otras ramas distintas y fundar una teoría general de la interpretación. A continuación los cánones a los que Betti hace referencia:

i) Canon de la inmanencia o canon de la autonomía hermenéutica.Referida a la intención de aprehender el espíritu o pensamiento del legislador.

ii) Canon de la totalidad y coherencia de la consideración hermenéutica.Referida a la correlación existente entre las partes constitutivas de un todo común y la reciproca iluminación del significado entre el todo y sus elementos constitutivos.

iii) Canon de la actualidad del entender.- Referida a la exigencia del sujeto de captar la norma, adaptarla y aplicarla al caso, ya sea de manera extensiva, restrictiva o, aun, analógica.

iv) Canon de la adecuación al entender.- o canon de la correspondencia o consonancia hermenéutica, por el cual el intérprete debe esforzarse en poner la propia actualidad en intima adhesión y armonía con la incitación que le llega al objeto, de modo que a una y otro vibren en perfecto unísono.

\section{- Interpretación in dubio pro fisco e in dubio pro contribuyente}

Tarsitano señala que los adagios latinos in dubio pro fisco e in dubio pro contribuyente, expresan criterios destinados a atribuir efectos predeterminados 
al sentido no evidente de la ley. Asimismo, señala que estos estilos ya se consideran superados en la dogmática tributaria, y que en todo caso se tratará de un punto de llegada y no de partida. Cita como ejemplo, la combinación del método gramatical con los principios de tipicidad legal y seguridad jurídica, podría predisponer al intérprete, a reformular el principio pro contribuyente que significaría que en caso de duda no puede haber impuesto, o en sentido inverso, entender que la exención tributaria se interpreta con alcance restrictivo. (Tarsitano, 2003, págs. 411 - 459)

Vanoni concluye acerca de este concepto, que no puede determinarse apriorísticamente que la ley beneficie al quien percibe el tributo o al que lo pague. (Vanoni, 1973)

\section{- Interpretación auténtica, jurisprudencial y doctrinal}

De acuerdo a la fuente de la interpretación, la doctrina la clasifica en autentica, jurisprudencial y doctrinal, según Tarsitano (Tarsitano, 2003). A continuación el desarrollo de las mismas:

\section{○ Interpretación Auténtica}

Es la que realiza el propio órgano del cual emana, Tarsitano agrega que cuando se habla de legislador como fuente de producción normativa, lo hace con la referencia estricta al principio de reserva de legal. Agrega que, la interpretación auténtica es un remedio excepcional, y así como la interpretación que sienta es indubitable, no es sencillo, más allá de la manera como el productor de la norma califique, determinar si la norma consagra la interpretación auténtica de la precedente o la pretende modificar con carácter retroactivo.

En el ámbito tributario, la utilización de ésta interpretación genera sensaciones encontradas, puesto que, de cara al futuro la aclaración proporciona certeza y previsibilidad, sin embargo, en cuanto al pasado, puede significar un atajo para zanjar una disputa que debe ser resuelta en sede judicial. A juicio de Tarsitano, se pueden discutir los efectos que provoca la norma auténtica o aclaratoria, sin embargo, para él, dos resultan claros, si se admite la interpretación auténtica, ella debería aplicarse retroactivamente a la norma interpretada, haciendo referencia a Linares 
(Linares Quintana, 1951). Sin embargo, ello no significa sostener que existe retroactividad en materia tributaria, ya que el hecho imponible ya sucedió, y no puede haber intereses resarcitorios, recargos y sanciones, por el incumplimiento anterior a su dictado.

\section{○ Interpretación Jurisprudencial}

Es la realizada por el, o, los órganos jurisdiccionales, y su importancia radica en que se construye una doctrina que contribuye a la elaboración dogmática de la disciplina de acuerdo a Tarsitano (Tarsitano, 2003). Krause, señala que la más importante, por su jerarquía y sentido uniformador, es la jurisprudencia de la Corte Suprema de Justicia ${ }^{13}$, que deberían seguir los tribunales inferiores dado que, su carácter interprete supremo del orden jurídico nacional hace que las decisiones de los jueces que se aparten de sus criterios, carezcan de fundamento y de validez, o en su caso justifiquen dicho apartamiento. (Krause Murguiondo, 2000)

\section{○ Interpretación doctrinal}

Es la realizada por los estudiosos del derecho tributario sobre la relación existente entre la ley, el universo hipotético de casos comprendido en ella y las categorías teóricas, arguye Tarsitano (Tarsitano, 2003). Su objeto de estudio se dirige a desentrañar el sentido genérico de la norma, mediante construcciones científicas y elaboraciones dogmáticas, en consecuencia, se prescinde de la aplicación de la norma a casos concretos.

\subsubsection{Métodos de interpretación genéricos en el derecho tributario}

A continuación lo métodos de interpretación del derecho, a partir de los cuales ensayar una interpretación de la regla de subcapitalización puesta en el quinto párrafo de artículo 37.a) de la Ley del IR.

\section{- Interpretación gramatical}

\footnotetext{
${ }^{13}$ En referencia al ordenamiento de justicia de Argentina
} 
Viene a ser la primera aproximación al alcance de la Ley, según Tarsitano, para la compresión del lenguaje empleado, situación que conlleva a atribuirle un significado a las palabras, por medio de reglas semánticas y de orden sintáctico establecido (Tarsitano, 2003, págs. 411 - 459). Añade que la Corte Suprema ${ }^{14}$ mediante Fallos 3112:2079

La primera fuente de exegesis de la ley es su letra y cuando ésta no exige esfuerzo de interpretación debe ser aplicada directamente con presidencia de consideraciones que excedan las circunstancias del caso expresamente contemplado por la norma. De otro modo podría arribarse a una interpretación que, sin declarar la inconstitucionalidad de la interpretación legal, equivaliese a prescindir de su texto.

En el mismo sentido, los Fallos 307:928 señalan que

La claridad de las normas referidas impone apegarse, para la resolución del tema debatido, al principio sostenido reiteradamente por esta corte, conforme al cual la primera fuente de interpretación de la ley es su letra, sin que sea admisible una inteligencia que equivalga a prescindir del texto legal si, como es el caso, no media debate y declaración de inconstitucionalidad, pues la exegesis de la norma, aun con el fin de adecuación a principios y garantías constitucionales, debe practicarse sin violación de su letra o de su espíritu (fallos, 300:687, y 301:958)

Para Tarsitano, el lenguaje que emplea el legislador posee un sentido técnico jurídico. Este sentido revela, a veces, con palabras o expresiones de contenido particular a la disciplina jurídica (i.e. tributo, impuesto, tasa, prescripción, dolo) y en otras ocasiones, por medio del sentido usual de las palabras y expresiones que contienen las proposiciones normativas.

Asimismo, citando a Garcia señala que de acuerdo al resultado que se alcanza con la interpretación gramatical, la doctrina, en general, coincide en designar como interpretación (i) literal o estricta aquella que declara el texto evidente de la norma, (ii) restrictiva la que disminuye el alcance que surge del tenor literal de las palabras, y (iii) extensiva la que lo transporta hacia la intención de la ley, más allá de las palabras, esto último citando a los fallos 237:33. (Garcia Belsunce, 1994)

${ }^{14}$ Argentina 


\section{- Interpretación teleológica}

Bajo este método, alcanzar el fin de la ley constituye el norte del intérprete, según Tarsitano. Añade que es un resultado antes que un método, un producto que se procura antes que el medio para obtenerlo. Marca el límite externo de la labor regenerativa del intérprete, que construirá la solución al caso moviéndose entre la letra y el fin de la ley. La búsqueda del espíritu de la ley, devuelve una versión sustancialista del derecho, que se concreta de manera efectiva en tanto conecta la realidad con el principio de justicia, y actual debido a que enlaza la voluntad de la ley con la realidad. (Tarsitano, 2003, págs. 411 - 459)

Vanoni destacó que el fin de la labor del intérprete no es investigar la inexistente voluntad de los órganos creadores de la ley, sino aprehender el valor de la ley, considerado como voluntad viva del Estado. (Vanoni, 1973)

Gonzalez (González García, 1997) recurre a una metáfora:

La interpretación es como un fuelle o un resorte, que está contenido entre los extremos de la letra y el fin de la ley. Se puede estirar o acortar, pero posee un límite más allá del cual no puede dilatarse o encogerse

Tarsitano (Tarsitano, 2003) recuerda que:

La obligación tributaria nace con la verificación del hecho imponible, el cual es uno jurídico con sustancia económica. El contenido económico se eleva a capacidad contributiva al ser capturado por la ley como categoría imponible, de ahí que el fin dela ley se alcanzar esa capacidad contributiva, que se conecta a una manifestación económica. Identificar esa capacidad contributiva como hecho jurídico incorporado a la norma, forma parte de la tarea del interprete, más allí debería agotarse toda la proyección y la referencia al fundamento económico de la norma tributaria.

\section{- Interpretación sistemática}

Krause, señala que dentro del marco de la sistematización del orden jurídico, se deben encontrar solución a los problemas y contradicciones entre normas, 
de las redundancias normativas y de las falsas presuposiciones fácticas o jurídicas, que pueden contener las leyes. (Krause Murguiondo, 2000)

De acuerdo a Tarsitano, la ley tributaria a interpretar forma parte de un sistema jurídico complejo, así la ley del impuesto a las ganancias forma parte del sistema fiscal al que se vincula por normas y principios generales, y dentro de ella, por ejemplo, el precepto referido a las condiciones de incobrabilidad de un crédito para cargarlo a resultados, integra el subsistema de determinación de la renta gravada. En todos los niveles se establecen relaciones funcionales que procuran unidad, coherencia e integración entre las distintas instituciones que figuran en el sistema, y de estas relaciones (verticales y horizontales, de subordinación y coordinación) emergen operaciones de abstracción a principios generales, inferencias, deducciones, correspondencias, exclusiones, implicancias, entre otras, agrega que el intérprete debe construir la solución al caso clasificando el material jurídico con método sistemático, identificar la función que desempeña cada norma individual dentro del conjunto al cual pertenece y establecer principios ordenadores. (Tarsitano, 2003, págs. 411 459)

Sobre el particular Soler (Soler, 1962), ha señalado:

Se hace por ello indispensable fijar su sentido jurídicamente valido -que lo tieneprecisamente porque la vaga generalidad de los enunciados favorece la actitud de acordar a esos principios un origen científico, filosófico o metafísico extrajurídico, y, como tales, despojados de la capacidad fundante propia de la normas dotadas de validez. Un principio jurídico, por general que sea, que no procede de alguna de las fuentes de producción constitucionalmente legítimas, carecerá de poder obligante y permanecerá dentro del ámbito fluctuante de las opiniones de los ideales y de la política.

\section{- Interpretación lógica}

Para Tarsitano (Tarsitano, 2003) constituirá una obviedad decir que la ley se interpreta de manera lógica o, que el intérprete usa la lógica en su actividad de conocimiento de la ley, Ni aún los partidarios del intuicionismo propiciado por otro autores, citando a Gény [citado por Sebastian Soler (Soler, 1962)], negaría 
tal afirmación. Añade que autores como Ihering y Gény, encaminaron sus críticas contra los excesos de la llamada Begriffjurisprudenz, que presentaba el derecho como un orden cerrado de conceptos, que originaba una especie de geometría jurídica. Prevalecía en ellos una visión escéptica referida a los conceptos, de manera tal se apuntalaba al corazón de la interpretación como producto de la lógica o de la razón, lo que implica reconocer la limitación de la inteligencia.

De acuerdo a Tarello citado en el libro de Andrea Amatucci (Amatucci, 2001) y Norberto Godoy (Godoy, 1992), el primero desarrolla algunos argumentos de lógica interpretativa: (i) el argumento a contrario, (ii) el argumento a simili ad simile (analogía), (iii) el argumento a fortiori, (iv) el argumento de la plenitud de la disciplina jurídica, (v) el argumento de coherencia de la disciplina jurídica, (vi) el argumento psicológico (o recurso de la voluntad del legislador concreto), (vii) el argumento histórico (o presunción de continuidad o hipótesis del legislador conservador), (viii) el argumento apagógico (o ad absordum o reductio ad absordum) o hipótesis del legislador razonable, (ix) el argumento teleológico (o hipótesis del legislador provisto de fines), (x) el argumento económico (o hipótesis del legislador no redundante), (xi) el argumento de la de autoridad (o ad exemplum), (xii) el argumento sistemático (o hipótesis del derecho ordenado), (xiii) el argumento naturalístico (o de la naturaleza de las cosas, o hipótesis del legislador impotente), (xiv) el argumento equitativo, y (xv) el argumento a partir de principios generales (analogía iuris).

Para las teorías axiomático-analíticas, que conciben el derecho como un silogismo lógico-jurídico, la lógica formal alcanza para hacer derivar un resultado valido de la concatenación entre premisa mayor, premisa menor y consecuencia.

Concluye Tarsitano, que la lógica en sí misma no alcanza para ser un método de interpretación independiente. Bajo su perspectiva:

La lógica es usada en la interpretación para deducir consecuencias normativas que correlacionan el caso son su solución, lo que lleva a sumergir la causa material subyacente a todos los métodos de interpretación. 


\subsection{Interpretación del artículo 37.a) de la Ley del IR}

Si bien la doctrina ha conceptualizado las diferentes técnicas y métodos de interpretación del derecho en general y, en especial, del derecho tributario, la afirmación de Tarsitano (Tarsitano, 2003), sin duda, describe el proceder de todo interprete del derecho, llámese; juez, vocal, auditor, asesor, entre otros; que en su camino de desentrañar la norma y realizar una interpretación de acorde a los cánones del derecho, conjuga los elementos: gramatical, lógico, histórico y sistemático, antes de usarlos aisladamente como métodos únicos de interpretación.

Es decir, la interpretación de la norma tributaria y de cualquier norma en general, no necesariamente será atribuida a un método o técnica interpretativa, sino más bien, será el resultado de la utilización combinada de cada una. Una más que otra, dependiendo de la norma y/o hecho económico materia de análisis.

Resulta evidente que la principal discusión sobre la regla de subcapitalización, es si ésta como se encuentra redactada (intereses provenientes de endeudamientos), comprende a cualquier figura de endeudamiento sea directo o indirecto, En ese sentido, a efectos de ensayar una interpretación de la regla de subcapitalización establecida en la Ley del IR, consideramos que la misma puede ser deducida desde dos perspectivas, en función a los métodos de interpretación:

\subsubsection{Interpretación literal de la regla de subcapitalización}

Conviene para estos efectos, citar a la letra el quinto párrafo del artículo 37.a) de la Ley del IR, que señala:

Serán deducibles los intereses provenientes de endeudamientos de contribuyentes con partes vinculadas cuando dicho endeudamiento no exceda del resultado de aplicar el coeficiente que se determine mediante decreto supremo sobre el patrimonio del contribuyente; los intereses que se obtengan por el exceso de endeudamiento que resulte de la aplicación del coeficiente no serán deducibles.

Para un sector de la doctrina, en este caso Montestruque (Montestruque, 2006, págs. 255271), 
[...] nuestra LIR se refiere únicamente a "endeudamiento" sin distinguir si el mismo debe ser uno directo o indirecto. No obstante, entendemos que puede configurarse cualquiera de dichos supuestos a fin de que sea aplicable la norma bajo comentario. En todo caso, consideramos que el endeudamiento indirecto está comprendido al darse la posibilidad de que existan supuestos de vinculación a través de sujetos interpuestos [...]

Sin embargo, la misma autora, en referencia a los presupuestos de aplicación de la regla de subcapitalización, señala:

Hemos dicho también que el endeudamiento puede ser directo o indirecto. El primero no ofrece, por obvio, mayor comentario. Sin embargo, en cuanto al endeudamiento indirecto se presentan algunos problemas de interpretación por la falta de precisión de los conceptos empleados

Añade:

Debe indicarse que lo que el legislador pretende con la mención a "endeudamiento indirecto" es evitar situaciones de elusión fiscal para la aplicación de la norma antisubcapitalización, por la interposición, entre el prestamista y prestatario, de personas o entidades independientes. Lo que finalmente se busca es cubrir el espectro más amplio de situaciones posibles.

Cuando cita al legislador y su mención al endeudamiento indirecto, se entiende que hace referencia a la legislación comparada.

No obstante la autora en principio afirma que al no distinguir la norma entre endeudamiento directo e indirecto, se entiende que puede configurarse cualesquiera de los supuestos, y concluye que el endeudamiento indirecto se encuentra comprendido al existir la posibilidad de que existan supuestos de vinculación a través de sujetos interpuestos. No obstante, en la segunda parte de la cita, (i) reconoce que en lo concerniente al endeudamiento indirecto existen problemas de interpretación, y (ii) señala que el legislador de otra jurisdicción incluyó al endeudamiento indirecto, con el objeto evitar situaciones de elusión fiscal; evidenciándose cierta contradicción en los comentarios de la misma autora.

En ese sentido, si realizamos una deducción literal de la norma, se pueden arribar a dos conclusiones: (i) que dada la redacción de la norma, las figuras de endeudamiento sean estos directos o indirectos, se encuentran comprendidos dentro la regla de subcapitalización, y (ii) que la norma únicamente incluye los endeudamientos directos, ya que la norma no ha hecho tal distinción. 
Si bien, se puede sostener que un aforismo ${ }^{15}$ del derecho señala que "Nadie debe distinguir donde la ley no distingue", considero que no resulta un elemento suficiente para señalar que cuando la norma refiere a endeudamiento, se debe colegir que incluye tanto al directo como al indirecto.

\subsubsection{Interpretación teleológica y sistemática de la regla de subcapitalización}

Como se expuso en numerales previos, la interpretación idónea es aquella que conjuga los elementos o métodos de interpretación, que en este caso los observaremos desde dos perspectivas:

\section{- Interpretación por los fines y objeto de la ley o teleológica}

Desde la perspectiva societaria y financiera, la subcapitalización es el fenómeno por el cual el financiamiento propio (vía aporte de capital), es significativamente inferior al financiamiento externo (vía préstamo) proveniente de los mismos propietarios. Tal fenómeno obedece al objetivo de reducción del riesgo empresarial, y consecuente obtención de rendimientos para el propietario más allá del resultado de la Compañía.

De otro lado, de acuerdo a las posiciones descritas en el Capítulo I, se resume que desde la perspectiva fiscal, la infracapitalización o subcapitalización supone el establecimiento de figuras tributarias anómalas, con el objeto de obtener ventajas fiscales a partir de reducir la renta imponible en la jurisdicción del prestamista, para eventualmente sujetarlos a imposición en una jurisdicción con una tasa inferior a la del país del prestamista.

En ese sentido, si la norma es analizada desde el punto de vista de la intención del legislador, en este caso, con el fin de combatir supuestos de elusión fiscal por medio de la erosión de la base tributaria, correspondería señalar que la norma resulta de aplicación en los casos en los que se acredite que el contribuyente tuvo la intención de erosionar la dicha base imponible.

\section{- Interpretación por comparación de normas o sistemática}

\footnotetext{
${ }^{15}$ En referencias a los aforismos $\mathrm{R}$ de Ruggiero
} 
En este caso, resulta adecuado con el método de interpretación sistemática, realizar un análisis conjunto de las normas que regulan los supuestos de endeudamiento, como son la norma que regula el impuesto a la renta aplicable a los intereses en favor de no domiciliados y la norma que regula la deducibilidad de las gasto por impuesto asumido, en el caso de endeudamiento provenientes del exterior.

\section{○ Norma de retención de impuesto a la renta por interés}

Resulta conveniente traer a colación el supuesto en el cual la norma peruana si incorporó, en otro supuesto normativo, el tratamiento de los endeudamientos indirectos. El artículo 56.j) ${ }^{16}$ de la Ley del IR señala:

El impuesto a las personas jurídicas no domiciliadas en el país se determinará aplicando las siguientes tasas:

(...) los intereses que abonen al exterior las empresas privadas del país por créditos concedidos por una empresa del exterior con la cual se encuentra vinculada; o los intereses que abonen al exterior las empresas privadas del país por créditos concedidos por un acreedor cuya intervención tiene como propósito encubrir una operación de crédito entre partes vinculadas: treinta por ciento $(30 \%)$.

(...) se entiende que existe una operación de crédito en donde la intervención del acreedor ha tenido como propósito encubrir una operación entre empresas vinculadas, cuando el deudor domiciliado en el país no pueda demostrar que la estructura o relación jurídica, adoptada con su acreedor coincide con el hecho económico que las partes pretenden realizar.

Sobre la norma descrita cabe precisar dos aspectos:

i. La aplicación de la tasa de retención del 30\% cuando el endeudamiento proviene de partes vinculadas, y no del $4.99 \%$ que es aplicable en al caso de préstamos con terceros independientes no domiciliados. Y,

\footnotetext{
${ }^{16}$ Incorporado por la Ley 29645 publicada el 31.12.2010, vigente a partir del 01.01.2011.
} 
ii. La aplicación de la misma tasa del $30 \%$ cuando se tratan de operaciones encubiertas.

En relación a lo segundo, Esquives, considera que el último párrafo de este inciso establece una obligación indebida para el sujeto domiciliado, ya que se le estaría exigiendo probar un hecho que en principio debiera ser inexistente, es como exigir a alguien probar que no cometió un acto ilícito. En ese sentido la carga de la prueba la tendrá al Administración. (Esquives Espinoza, 2012, págs. 73-94)

Más allá de la posición descrita en el párrafo precedente, que dicho sea de paso resulta atendible, esta norma de encubrimiento ha sido considerada por la doctrina como una regla back to back, conceptualización que no será materia de análisis del presente trabajo.

Resulta de importancia resaltar que a diferencia de la regla de subcapitalización, que ha establecido como elementos mínimos para su aplicación: (i) la existencia de un crédito o endeudamiento, y (ii) la actuación de partes vinculadas; la norma del impuesto a la renta (artículo 56.j) en relación al sujeto no domiciliado que las obtiene, ha establecido una tasa (de excepción) de retención del 30\%, cuando (i) existe un crédito o endeudamiento, (ii) la operación es entre partes vinculadas, y agrega un tercer supuesto (iii) cuando se presenta la existencia de un tercer actor (independiente) como encubridor.

En ese sentido, al realizar una comparación o interpretación sistemática de ambas normas, se observa que el legislador para una misma operación (vista desde perspectivas distintas, (i) deducibilidad del gasto financiero y (ii) tasa de retención del IR), no equiparó el tratamiento fiscal.

\section{○ Norma sobre el impuesto asumido en el caso de intereses}

En lo que se refiere al tratamiento de los intereses pagados por sujetos domiciliados en el Perú, en favor de no domiciliados, conviene señalar que el artículo $47^{\circ}$ de la Ley del IR, ha establecido un régimen de excepción para el impuesto a la renta que grava tales intereses, cuando el sujeto domiciliado asume dicho impuesto. 
Así, el artículo $47^{\circ 17}$ señala:

El contribuyente no podrá deducir de la renta bruta el Impuesto a la Renta que haya asumido y que corresponda a un tercero. Por excepción, el contribuyente podrá deducir el Impuesto a la Renta que hubiere asumido y que corresponda a un tercero, cuando dicho tributo grave los intereses por operaciones de crédito a favor de beneficiarios del exterior. Esta deducción sólo será aceptable si el contribuyente es el obligado directo al pago de dichos intereses [...]

El artículo descrito, establece que el impuesto a la renta que grave los ingresos por intereses de un sujeto no domiciliado, que uno domiciliado asuma, excepcionalmente serán deducibles para la determinación de la renta neta, no obstante la regla general es que dicho impuesto no sea deducible, tal como fluye del mismo artículo.

A diferencia del artículo $47^{\circ}$ de la Ley del IR, la regla de subcapitalización ha agregado para su aplicación la existencias de partes vinculadas, mientras que el artículo 56.j) de la Ley del IR, fue un paso más adelante y regula adicionalmente las operaciones encubiertas o back to back.

Por lo expuesto, considero que la utilización del método teleológico y sistemático, son los idóneos para la interpretación de la regla de subcapitalización de la Ley del IR, puesto que recoge dos aspectos sustanciales; (i) el objetivo o sentido de la norma, y (ii) la visión de todo el espectro fiscal que regula los supuestos financiamiento; dejando de lado el método literal, como método único, sino más bien como herramienta inicial de interpretación.

En el siguiente y último capítulo, se consolidaran y presentarán las principales situaciones materia de estudio, así como las conclusiones preliminares, para así exponer las conclusiones y recomendaciones finales.

${ }^{17}$ Artículo incorporado en el Decreto Legislativo No 774, publicado en fecha 30.12.1993 


\section{CAPÍTULO IV: APLICACIÓN DE LA REGLA DE SUBCAPITALIZACIÓN, EN EL MARCO DE LOS CONTRATOS DE CASH POOLING}

Como fue desarrollado en el primer capítulo, en el contrato de cash pooling se observan dos aspectos resaltantes, las operaciones de crédito que derivan en gastos financieros por intereses, y la intervención de partes vinculadas. Esto último supone la revisión y potencial aplicación de la regla de subcapitalización prescrita en la Ley del IR.

En tal sentido el presente capítulo se centrará en determinar, si bajo lo expuesto en los capítulos precedentes, se puede colegir si la regla de subcapitalización establecida en el la Ley del IR, resulta de aplicación a los contratos de cash pooling.

\subsection{Los objetivos de los contratos de cash pooling, y su repercusión fiscal}

En principio, resulta claro que el contrato de cash pooling persigue objetivos únicamente financieros y administrativos -sin descartar que existan situaciones de simulación, con la búsqueda de mecanismos de planeación tributaria-, esto es, optimizar el manejo centralizado de la tesorería de los grupos empresariales, cuyos partícipes son empresas vinculadas respaldadas por la empresa matriz, al mismo tiempo se ha convertido en un producto financiero atractivo.

Si bien técnicamente existen dos tipos de contratos claramente demarcados, el Cash Pooling de Balance Cero y Cash Pooling Nocional o Virtual; es claro que primero es el tipo de contrato materia de análisis, por cuanto en él se evidencian operaciones reales de financiamiento. A diferencia del segundo, en el que solo ocurren movimientos de efectivo nocionales o contables.

A efectos prácticos, un contrato de cash pooling supone el endeudamiento o crédito obtenido por un sujeto domiciliados, de una entidad financiera no domiciliada, en el marco de un contrato, por el cual la casa matriz no domiciliada del sujeto domiciliado y el resto de subsidiarias no domiciliadas que dicha matriz controla, acordaron que la entidad financiera actúe como pooler, y administre los fondos del grupo, tomando los 
excesos de liquidez de las subsidiarias superavitarias en caja, recolocándolas, a través de líneas de crédito, en aquellas subsidiarias de posición deficitaria, devengando intereses para cada participe según su posición. Caro está, que el sujeto domiciliado se encuentra en una posición subcapitalizada, es decir que la deuda excede en tres (3) veces su patrimonio.

En tal sentido, la realización de un contrato de cash pooling, detonará los siguientes efectos, en principio de carácter financiero contable, al mismo tiempo que tributarios:

- Para la entidad financiera o pooler no domiciliada, se generan ingresos por intereses. Los cuales calificarán como rentas de fuente peruana, y estarán sujetas al impuesto a la renta, vía retención.

- El sujeto domiciliado registrará gastos financieros por los intereses pagados, los cuales para ser deducibles deberán someterse al artículo 37.a) de la LIR. Considerando que dichos gastos superan la barrera de la causalidad, corresponderá evaluar la barrera de la subcapitalización.

En relación al último punto, es claro que los contratos de cash pooling, efectivamente constituyen operaciones de financiamiento entre partes vinculadas, sin embargo, considero que los mismos no califican como operaciones de endeudamiento directo, sino indirecto, por la actuación de pooler, (en este caso entidad financiera). Así las cosas, el presente trabajo centra su atención en la aplicación o no, de la regla de subcapitalización a este modelo de contrato, a partir de las consideraciones detalladas. Por tanto, corresponde en el siguiente subtitulo, revisar detenidamente el aspecto conceptual del fenómeno de la subcapitalización.

\subsection{La naturaleza de la regla de subcapitalización, y su inclusión en la Ley del IR}

La infracapitalización o subcapitalización supone el establecimiento de figuras tributarias anómalas, con el fin de obtener ventajas fiscales a partir de reducir la renta imponible en la jurisdicción del prestatatario, y así eventualmente, sujetarlos a imposición en una jurisdicción con una tasa del impuesto a las ganancias inferior al de dicha jurisdicción. 
De acuerdo a lo desarrollado en el segundo capítulo, las reglas de subcapitalización y transparencia físcal internacional, fueron desarrolladas para combatir supuestos de elusión tributaria, practicada a través de la erosión de bases imponibles. Este concepto resulta de importancia, puesto que se configura como el fin del establecimiento de la regla de subcapitalización, combatir supuestos de elusión fiscal. En ese sentido, a efectos de realizar una interpretación idónea de dicha regla, deberá tomarse en cuenta el objeto de la norma.

En cuanto a los elementos que concurren y gatillan la aplicación de la regla de subcapitalización, se tiene: (i) la participación de partes vinculadas, y (ii) la existencia de endeudamiento. Respecto a esto último se construye la principal observación a la norma, que a su vez viene a ser el principal cuestionamiento del presente trabajo a la Ley del IR, en cuanto a la comprensión o abarcamiento de los endeudamientos indirectos.

La legislación comparada, en este caso la española, ha desarrollado una regla de subcapitalización similar a la de la LIR -en cuanto a la aplicación del método objetivo-, con la diferencia de haber precisado, que se encuentran contemplados los supuestos de endeudamiento directo e indirecto. Esta diferencia en relación a nuestra legislación, ha permitido que los interpretes de la ley tributaria, como el Tribunal Supremo, la Dirección General de Tributos, y la doctrina, han sostenido que el endeudamiento indirecto hace referencia a los préstamos back to back, o también conceptualizado como operaciones encubiertas.

Pese a la redacción e interpretación de la norma de subcapitalización española, para autores como Garcia Novoa (Garcia Novoa, 2010, págs. 1-41), existen dudas sobre si el endeudamiento indirecto, incluye a modelos de financiamiento como el back to back. Ello evidencia un cuestionamiento a la norma, al cual -en nuestro caso- resulta complejo arribar, ya que en nuestra legislación ni siquiera se estableció el supuesto de endeudamiento indirecto expresamente. En ese sentido, he aquí uno de los cuestionamientos al quinto párrafo del artículo 37.a) de la LR o regla de subcapitalización.

En relación al párrafo anterior, a diferencia de la norma española, la Ley del IR únicamente hace referencia al supuesto de endeudamiento en general, evidenciando un vacío, que puede significar que la interpretación de se decante por una u otra conclusión, 
dependiendo de la metodología de interpretación que se pretenda utilizar. Este último aspecto será analizado en el subtítulo siguiente:

Otro aspecto a tener presente en el análisis de la inclusión de la regla de subcapitalización en nuestra legislación, es que, si bien nuestra legislación ha optado por combatir el fenómeno de la subcapitalización por medio del método objetivo - esto es la imposición de un límite máximo de endeudamiento entre parte vinculadas-, en casos específicos de resolución de controversias, los tribunales ${ }^{18}$ (españoles) han tomado como referencia el método subjetivo, señalando que la Administración Tributaria para aplicar la regla de subcapitalización, debía probar que el contribuyente tuvo por intención aludir la norma tributaria, antes que lograr un objetivo económico o financiero primigenio. Resulta conveniente resaltar esta acotación, puesto que no debe perderse de vista en la interpretación de la norma, el objetivo de la creación de la regla, como se ha descrito en el segundo párrafo del presente punto.

\subsection{Utilización del método teleológico y sistemático, en la interpretación de la regla de subcapitalización}

Como bien sostiene el profesor Tarsitano, los elementos gramatical, histórico, sistemático y lógico, antes de constituirse como métodos o técnicas interpretativas; dichos elementos, deben ser conjugados en el camino recorrido en el intérprete. En ese sentido, considero que para la interpretación del quinto párrafo del artículo 37.a) de la LIR, resulta necesaria la conjugación, principalmente, de los métodos teleológico y sistemático.

En principio, conviene traer a colación el sentido u objetivo de la implantación de la regla de subcapitalización, no solo en nuestra legislación, sino en general en todas las jurisdicciones donde se optó por esta regulación. En ese sentido, la razón de ésta regla fue la de combatir el fenómeno de la subcapitalización, que se configuraban como supuesto de elusión tributaria, practicada a través de la erosión de bases imponibles.

Significa entonces que, si practicamos una interpretación teleológica o casualista, para concluir que se configuran los supuestos que dan origen a la aplicación de la regla de subcapitalización, deberíamos verificar que el sujeto busco un fin fiscal, antes que uno económico o financiero puramente, y solo así, concluir que se está frente a un supuesto

${ }^{18}$ Resolución N 1825/2011 del Tribunal Supremo español. 
de elusión, y por ende aplicar la norma. En consecuencia, dado que los contratos de cash pooling persiguen únicamente objetivos de carácter administrativo y financiero, concluiría que no se configura el supuesto de hecho, por ende la norma no resulta aplicable.

De otro lado, a efectos de realizar una interpretación sistemática de la regla de subcapitalización, corresponde revisar adicionalmente el artículo 56.j) y $47^{\circ}$ de la LIR, los cuales han normado sobre el impuesto a la renta que grava los intereses obtenidos por sujetos no domiciliados (en este caso vinculados), y el sobre la deducibilidad del gasto por impuesto a la renta asumido, que grava los intereses pagados en favor de sujetos no domiciliados.

Como se observa, desde perspectivas fiscales diferentes, las normas expuestas regulan una misma operación, que son los intereses por crédito proveniente del exterior, salvo el artículo 37.a) que adicionalmente regula créditos entre vinculados domiciliado; estableciendo parámetros a diferente escala para su aplicación, como se aprecia a continuación:

- El artículo 56.j) establece es una salvedad a la a la regla general, en la cual la tasa del impuesto a la renta por intereses provenientes del exterior es del $4.99 \%$, sin embargo, en caso concurran (i) deuda, y (ii) partes vinculadas, corresponderá la tasa de retención del IR del 30\%. Agrega dicha norma un tercer elemento para la aplicación de la excepción, el encubrimiento o back to back.

- El quinto párrafo del artículo 37.a) del mismo modo es una salvedad a la regla general, en la cual todos los intereses son deducibles, y por excepción resultará de aplicación de regla de subcapitalización, en caso concurran dos elementos: (i) deuda, e (ii) intervención de partes vinculadas.

- El artículo $47^{\circ}$ establece que el gasto por impuesto asumido no es deducible, sin embargo, por excepción, la norma permite la deducibilidad de dicho gasto, cuando se trate del impuesto que gravó los intereses por créditos provenientes del exterior, para cual no se ha establecido ninguna restricción, más que la existencia de deuda.

Lo expuesto conlleva a concluir que a partir de los parámetros que impuso una de las normas -artículo 56.j)-, los mismos no podrían ser replicados para su aplicación en otra - 
artículo 37.a)-, como es el caso de la operaciones encubiertas o endeudamiento indirecto, dado que cada una debe ser vista como un compartimiento estanco, y limitar su aplicación según los disposiciones que el legislador dispuso para cada una.

Es decir, si inferimos que el endeudamiento indirecto se encuentra comprendido por la regla de subcapitalización peruana, se estaría utilizando la figura establecida por la norma que regula el IR en los intereses obtenidos por sujetos no domiciliados. Por ende, no se podría afirmar que cuando el quinto párrafo del artículo 37.a) hace referencia al endeudamiento, ello incluye al endeudamiento directo e indirecto; cuando el artículo 56.j), regulando la misma operación desde el punto de vista del prestamista, ha normado expresamente los supuestos de endeudamiento indirecto o back to back, a diferencia de la regla de subcapitalización.

Un elemento no menos importante, es el principio de interpretación a través del cual las normas de carácter excepcional, deben ser interpretadas de forma restrictiva. A estos efectos, es de notar que las tres normas expuestas, en el aspecto analizado, tienen en común que son normas de excepción, en consecuencia deben ser interpretadas de forma restrictiva. Consecuentemente, se aprecia un elemento adicional para sostener que cuando la regla de subcapitalización hace referencia al endeudamiento, no puede extender su alcance al endeudamiento indirecto.

Por todo lo señalado, bajo mi consideración el método teleológico o causalista, y sistemático, resultan idóneos para la interpretación de la regla de subcapitalización de la Ley del IR, en la medida que recogen dos (2) aspectos sustanciales, como son: (i) el objetivo o sentido de la norma, y (ii) la visión de todo el espectro fiscal que regula los supuestos financiamiento.

\subsection{Sobre la aplicabilidad de la regla de subcapitalización en los contratos de cash pooling}

De acuerdo a lo señalado en la parte introductoria, el objetivo principal de la presente investigación es determinar la aplicabilidad o no de la regla de subcapitalización establecida en la legislación peruana, en el marco de los contratos de cash pooling.

No obstante los contratos de cash pooling, constituyen operaciones de financiamiento entre partes vinculadas, considero que los mismos no califican como operaciones de endeudamiento directo, sino indirecto, por la actuación de pooler. 
Configurándose, desde la perspectiva fiscal, una especie de endeudamiento encubierto o back to back.

Dado que la regla de subcapitalización, importa al común de jurisdicciones por su carácter anti-elusivo, bajo mi consideración, resulta poco adecuado realizar un análisis e interpretación, sin observar su aplicación en otras jurisdicciones. Es por ello, que para la deducción de la citada regla en nuestra legislación, conviene mirar el derecho comparado, en este caso español. A diferencia del quinto párrafo del artículo 37.a) de la LIR, la norma española ha regulado expresamente los supuestos de endeudamiento directo e indirecto. Tal distinción cobra importancia debido a la complejidad y diversidad de casos que suponen los casos de endeudamiento indirecto, y su conceptualización como operaciones back to back.

A partir de una lectura sistemática de los artículos 37.a), 47º y 56.j) de la Ley del IR, se infieren que los parámetros que impuso una de las normas - esto es, el artículo 56.j)-, no podrían ser replicados para su aplicación en otra -esto es, el artículo 37.a)-, como es el caso de la operaciones encubiertas, back to back o endeudamiento indirecto, dado que para su ejecución, cada una debe ser vista como un compartimiento estanco, y limitar su aplicación según los disposiciones que el legislador dispuso para cada una. Es decir, si concluimos que el endeudamiento indirecto se encuentra comprendido por la regla de subcapitalización peruana, se estaría utilizando una ficción legal establecida por el artículo 56.j) de la LIR.

En suma a lo anterior, una interpretación teleológica o casualista, nos permite concluir que, únicamente se configuran los supuestos de la regla de subcapitalización, cuando se verifica que el sujeto persiguió un fin fiscal, antes que uno económico o financiero. Situación que no ocurre en los contratos de cash pooling.

Lo anteriormente expuesto, permite concluir que el gasto financiero registrado por un sujeto domiciliado (subcapitalizado), por intereses pagados a un sujeto no domiciliado (pooler), en el marco de un contrato de cash pooling, no se encontrará limitado por efecto del ratio máximo de endeudamiento, dado que la regla subcapitalización impuesta en el Ley del IR, no ha contemplado los supuestos de endeudamiento indirecto, como éste. 


\section{CONCLUSIONES}

- Los contratos de cash pooling suponen principalmente operaciones de centralización de tesorería corporativa, con subsidiarias distribuidas alrededor del planeta. Operaciones a partir de las cuales se producen situaciones de financiamiento, donde el pooler o banco, recoloca los excedentes de liquidez de aquellas subsidiarias con excedentes, en aquellas deficitarias, los cuales a partir de la posición de cada participe generan interese por pagar o cobrar, cuyos efectos fiscales son materia de estudio en el presente trabajo.

- La motivación de los contratos de cash pooling son de carácter netamente financiero por la reducción de costes, y administrativo por la centralización y mejor manejo de la tesorería corporativa, descartando la posibilidad de algún objetivo que persiga la obtención de beneficios fiscales. Sin perjuicio que se utilicen figuras como ésta, para fines de elusión fiscal.

- La regla de subcapitalización en el derecho tributario cumple una función antielusiva, al igual que las norma de transparencia fiscal internacional. Ello supone que su aplicación, más allá de su redacción, debe ser interpretada y orientada hacia los fines que justifican su génesis, evitando su aplicación en supuestos donde no existe elusión. A ésta interpretación causalista, se debe añadir que el contrato de cash pooling, persigue objetivos distintos a los fiscales.

- A partir de una lectura sistemática de los artículos 37.a), 47º y 56.j) de la Ley del IR, se infiere que los parámetros que impuso una de las normas -esto es, el artículo 56.j)-, no podrían ser replicados para su aplicación en otra-esto es, el artículo 37.a)-, como es el caso de la operaciones encubiertas, back to back o endeudamiento indirecto, dado que para su ejecución, cada una debe ser vista como un compartimiento estanco, y limitar su aplicación según los disposiciones que el legislador dispuso para cada una. evidenciando que, por omisión o desconocimiento, el legislador tributario no ha considerado el endeudamiento indirecto en las reglas de subcapitalización. 
- La legislación comparada, en este caso la española, ha desarrollado una regla de subcapitalización similar, con la precisión de haber añadido los supuestos de endeudamiento directo e indirecto. Sobre ello, el Tribunal Supremo, la Dirección General de Tributos, y la doctrina, han sostenido que el endeudamiento indirecto hace referencia a los prestamos back to back, o también conceptualizado como operaciones encubiertas. Supuesto regulado de manera expresa en el artículo 56.j) de la LIR.

- La regla de subcapitalización no es de aplicación al contrato de cash pooling cuando el prestatario es una compañía domiciliada y el prestamista y empresa vinculada intervinientes, son no domiciliados, puesto que tal situación se configura como una operación de endeudamiento indirecto entre partes vinculadas, y tal supuesto no ha sido recogido por la legislación local sobre la materia.
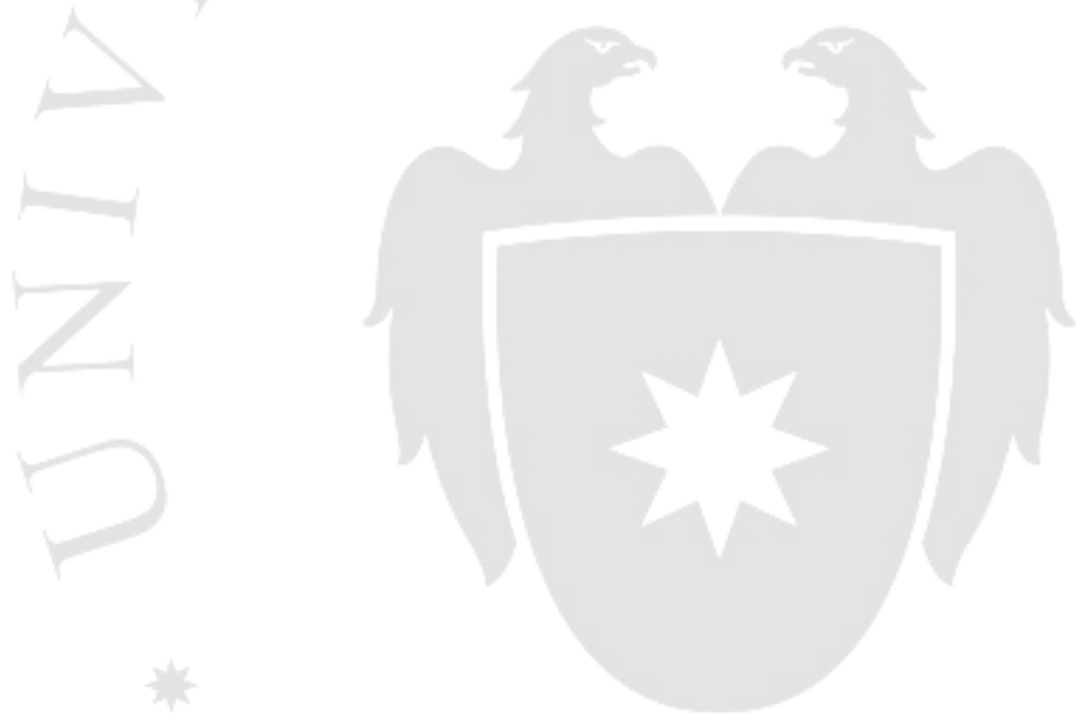


\section{REFERENCIAS}

AFI. (2009, Marzo 10). Cash Pooling Internacional. Informe Semanal (SAIE), 244, 1-6.

Altmeppen, H. (2010). Cash Pooling und Kapitalerhaltung in faktischen Konzern. NZG, 401.

Amatucci, A. (2001). Tratado de Derecho Tributario. Bogota: Temis.

Araoz Villena, L. A. (1992). La Interpretación Económica de la Leyes Tributarias y la Calificación De Los Hechos Imponibles por su Contenido Económico. Revista del Instituto Peruano de Derecho Tributario, 65-80.

Ausejo Gutiérrez, Z. M. (2013). La Técnica de la Interpretación de la Normas Jurídicas. Lima: Librería y Ediciones Jurídicas.

Barletta, F., Pereira, M., Robert, V., \& Yoguel, G. (2013). Argentina: dinámica reciente del sector de software y servicios informáticos. Revista de la CEPAL(110), 137155. Retrieved from http://www.cepal.org/publicaciones/xml/1/50511/RVE110Yoqueletal.pdf

Barriocanal Muñoz de la Espada, M. (2011). Cash pooling internacional: de la teoría a la práctica. Estrategia Financiera, 42-46.

Betti, E. (1975). Interpretación de la Ley y de los Actos Jurídicos. Madrid: Edersa.

Blanco, Á., \& Castro, L. Á. (2010). La Subcapitalización y el Derecho Comunitario. Crónica Tributaria: Boletín de Actualidad, 1-26.

Bullard Gonzales, A. (2007). Tratado de la Interpretaciónb del Contrato en America Latina. Lima: Editora Juridica Grijey E.I.R.L.

Castro Arango, J. (2013). La capitalización encubierta en la Reforema Tributaria de 2012: ¿transplante legal o engendro legal? Revista de Derecho del Estado, 161190.

Chevarría Arrieta, Z. M. (2009). La Subcapitalización en la Ley del Impuesto a la Renta y su Impacto en la Economía. Lima: Universidad de Lima.

Choy, M., \& Chang, G. (2014). Medidas macroprudenciales aplicadas en el Perú. Lima: Banco Central de Reserva del Perú. Retrieved from http://www.bcrp.gob.pe/docs/Publicaciones/Documentos-deTrabajo/2014/documento-de-trabajo-07-2014.pdf

Cordón, T., \& Gutiérrez, M. (2004). Manual de Fiscalidad Internacional. Madrid. 
Corona, J. (1992). Doble imposición económica e internacional de los dividendos. Madrid: Papeles de trabajo del Instituto de Estudios Fiscales.

De Diego, C. (1930). Instituciones de Derecho Civil; Introducción, Parte General, Propiedad, Derechos Reales. Madrid: Librería Torreón de Rueda.

Delgado Pacheco, A. (2005). Las medidas antielusión en la fiscalidad internacional. Nuevas Tendencias en economía y fiscalidad internacional, 97-118.

Du Pasquier, C. (1983). Introducción al Derecho. Lima: Ediciones y Distribuciones Justo Valenzuela E.I.R.L.

Esquives Espinoza, R. (2012). TRATAMIENTO EN LA LEY DEL IMPUESTO A LA RENTA RESPECTO DE LAS OPERACIONES DE FINANCIAMIENTO. Revista del Insituto Peruano de Derecho Tributario, 73-94.

Fuentes, M. (2014). El Contrato de "Cash Pooling". Revista de Derecho Mercantil, 233266.

Garcia Belsunce, H. (1994). Estudios de Derecho Constitucional Tributario (Homenaje a Juan Carlos Luqui). Buenos Aires: Depalma.

García Gonzáles, J., \& Zamora Valencia, F. (2012). The debt-equity conundrum. In I. F. Association, Cahiers de droit fiscal international (pp. 465-488). Rotterdam: Mixed Sources.

García Nieto, J. P. (2013). Consturye tu Web comercial: de la idea al negocio. Madrid: RA-MA.

Garcia Novoa, C. (2010). Neutralidad fiscal en la financiación de la empresas. El caso español. Estudios Tributarios Europeos, 1-41.

Garcia Toma, V. (1995). La Ley en el Perú. Elaboración, Interpretación, Aplicación e Interpretación. Lima: Editorial Grijley.

Godoy, N. (1992). Teoria general del Derecho Tributario. Buenos Aires: AbeledoPerrot.

González García, E. (1997). La Interpretación de las Normas Tributarias. Pamplona: Aranzadi.

Griziotti, B. (1959). Principios de la Ciencia de las Finanzas. Buenos Aires: Depalma.

Joo Garfias, E. A. (2008, Junio). La Regla de Subcapitalización en la Legislación Peruana y su Compatibilidad con los Convenios Para Evitar la Doble Imposición Tributaria. Lima, Lima, Perú.

Krause Murguiondo, G. (2000). La Interpretación de la Ley y el Derecho Tributario. Buenos Aires.

Leander, T. (2015). CHINA, THE RENMINBI AND THE WORLD. Global Finance, 30-31. 
Linares Quintana, S. (1951). El Poder Impositivo y la Libertad Individual. Buenos Aires: Alfa.

Messineo, F. (1956). Manual de Derecho Civil y Comercial: Introducción al Ordenamiento Jurídico. Buenos Aires: Ediciones Jurídicas Europa-America.

Miola, M. (2011). Tesoreria accentratta nei gruppi di societa e capitale sociale. 41.

Montestruque, K. (2006). Aspectos Fiscales de la Subcapitalización de Sociedades y su Regulación en el Perú. Rvista Peruana de Derecho de la Empresa, 255-271.

Niehus, U., Wilke, H., \& Müller, A. (2013). El régimen Alemán de la limitación de la deducibilidad de gastos financieros (Zinsschranke). CRONICA TRIBUTARIA, 221-245.

Ortega, F. j. (2005). Modelo para implantar una tesorería centralizada en un grupo empresarial. Estrategia Financiera, 20-28.

Palao, C. (2012). Fiscalidad Internacional. Madrid.

Pita Grandal, A. M. (1998). Una aportación sobre la naturaleza juridica de la norma sobre subcapitalización en España. Doctrina Cientifica, 11-22.

Reale, M. (1984). Introducción al Derecho. Madrid: Piramide S.A.

Rey, F., \& Collado, A. (1993). Aspectos fiscales de la subcapitalización de sociedades: Derecho comparado. In M. Pons, Impuestos (Vol. II, pp. 80-97). Madrid.

Ross, A. (n.d.). Sobre el Derecho y la Justicia. Buenos Aires: Editorial Universitaria de Buenos Aires.

Rubio Correa, M. (1985). El Sistema Jurídico. Introducción al Derecho. Lima: Fondo Editorial PUCP.

Ruggeri, L. (2011). Brevi Note Circa Il Cash Pooling. Il Caso, 1-10.

Sanz Gadea, E. (2001). MEDIDAS ANTIELUSIÓN FISCAL. Madrid: Instituto de Estudios Fiscales.

Savigny, V. (2009). Sistema del Derecho Romano Actual. Madrid: Biblioteca Virtual Miguel de Cervantes.

Serrano Olivares, R. (2014). GRUPOS DE EMPRESA A EFECTOS LABORALES Y CASH POOLING. IUSLabor, 7.

Soler, S. (1962). La Interpretación de la Ley. Barcelona: Ariel.

SUNAT, S. N. (2002, Enero 08). Informe Nº 005-2002-SUNAT/K00000. Lima, Lima, Perú. 
Szlęzak-Matusewicz, J. (2014). Tax Risk in Cash Pooling Agreements in Polish Enterprises . Management Theory and Studies for Rural Business and Infrastructure Development, 977-987.

Tarsitano, A. (2003). Interpretación de la Ley Tributaria. In H. Garcia Belsunce, Tratado de Tributación (pp. 411 - 459). Buenos Aires: Astrea.

Valencia Zea, A. (1981). Derecho Civil: Parte General y Personas. Bogota: Temis S.A.

Vanoni, E. (1973). Naturaleza e Intepretaciónn de las Leyes Tributarias. Madrid: Instituto de Estudios Fiscales.

Vega Borrero, F. A. (2002). La Norma Tributaria en Materia de Subcapitalización: Incidencia de los convenios de doble imposición y del derecho comunitario. Crónica Tributaria, 89-125.

Wittmann, R. (2006). ¿Hubo una revolución en la lectura a finales del siglo XVIII? In G. Cavallo, \& R. Chartier, Historia de la lectura en el mundo occidental (pp. 435-472). México D.F.: Santillana.
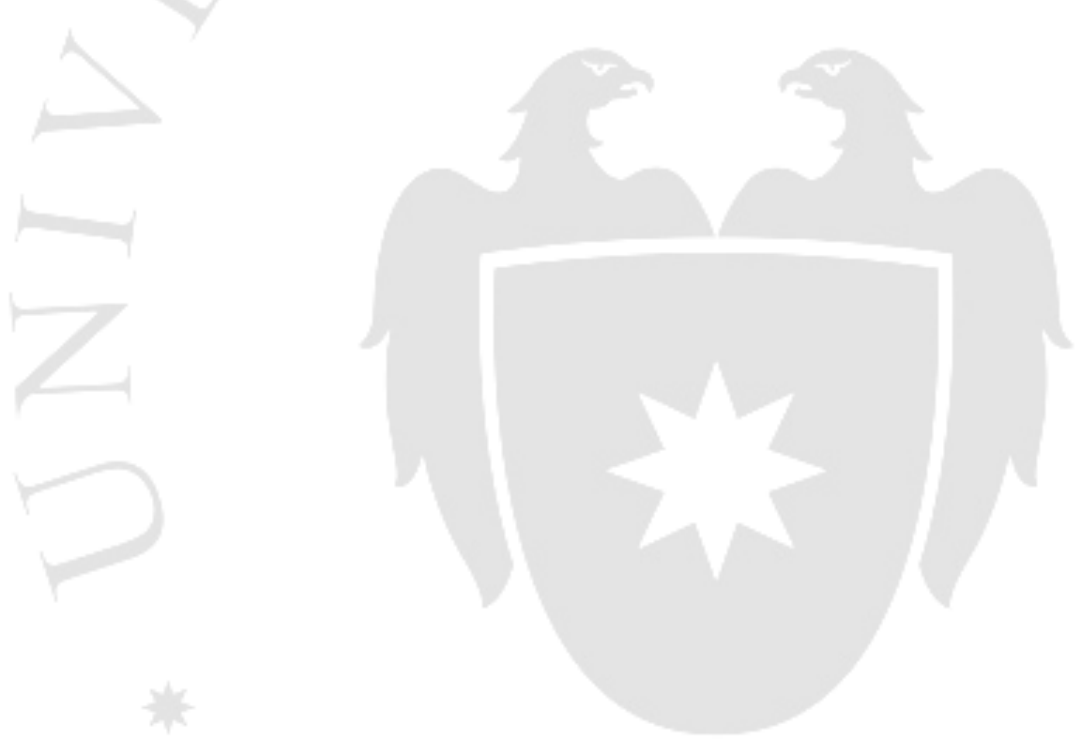